\title{
OPEN Role of myeloid cell leptin signaling in the regulation of glucose metabolism
}

\author{
Sandra Pereira ${ }^{1}$, Daemon L. Cline ${ }^{1}$, Melissa Chan ${ }^{1}$, Kalin Chai ${ }^{1}$, Ji Soo Yoon ${ }^{1}$, \\ Shannon M. O'Dwyer ${ }^{1}$, Cara E. Ellis ${ }^{1}$, Maria M. Glavas ${ }^{1}$, Travis D. Webber ${ }^{1}$, Robert K. Baker ${ }^{1}$, \\ Suheda Erener ${ }^{1}$, Scott D. Covey ${ }^{2} \&$ Timothy J. Kieffer ${ }^{1,3,4} \square$
}

\begin{abstract}
Although innate immunity is linked to metabolic health, the effect of leptin signaling in cells from the innate immune system on glucose homeostasis has not been thoroughly investigated. We generated two mouse models using Cre-lox methodology to determine the effect of myeloid cell-specific leptin receptor (Lepr) reconstitution and Lepr knockdown on in vivo glucose metabolism. Male mice with myeloid cell-specific Lepr reconstitution ( $L y z 2 C \mathrm{Cr}^{+} L e p r^{\text {loxTB/loxTB }}$ ) had better glycemic control as they aged compared to male mice with whole-body transcriptional blockade of Lepr ( $L y z 2 C r e^{-}$Lepr ${ }^{\text {loxTB/loxTB}}$ ). In contrast, $L y z 2 C r e^{+} L e p r^{10 x T B / l o x T B}$ females only had a trend for diminished hyperglycemia after a prolonged fast. During glucose tolerance tests, $L y z 2 C \mathrm{Cre}^{+} L e p r^{\mathrm{loxTB} / \mathrm{lox} T B}$ males had a mildly improved plasma glucose profile compared to $C \mathrm{Cr}^{-}$controls while $\mathrm{Lyz} 2 \mathrm{Cre}{ }^{+} \mathrm{Lepr}{ }^{\text {IoxTB/loxTB }}$ females had a similar glucose excursion to their Cre- controls. Myeloid cell-specific Lepr knockdown (Lyz2Cre+Lepr floxfflox) did not significantly alter body weight, blood glucose, insulin sensitivity, or glucose tolerance in males or females. Expression of the cytokine interleukin 10 (anti-inflammatory) tended to be higher in adipose tissue of male $L y z 2 C r e^{+} L e p r^{\text {loxTB/loxTB }}$ mice $(p=0.0774)$ while interleukin 6 (pro-inflammatory) was lower

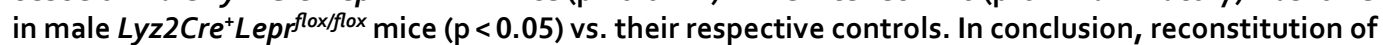
Lepr in cells of myeloid lineage has beneficial effects on glucose metabolism in male mice.
\end{abstract}

Macrophages can disturb glucose homeostasis and insulin sensitivity by secreting inflammatory cytokines ${ }^{1,2}$. The effect of leptin signaling in cells of myeloid lineage, which include macrophages, on glucose metabolism has not been thoroughly investigated. It has been reported that leptin increases canonical pro-inflammatory cytokine expression, but decreases canonical anti-inflammatory cytokine expression by monocytes/macrophages in vitro in a dose-dependent manner ${ }^{3-6}$. However, leptin has been found to induce a mixed M1 (pro-inflammatory) and M2 (anti-inflammatory) phenotype in monocytes/macrophages ${ }^{7}$ and also to increase anti-inflammatory cytokine expression $^{8}$. The long isoform of the leptin receptor (Leprb) is widely accepted to mediate most of the effects of leptin, including signal transducer and activator of transcription-3 (STAT3) activation, and leptin increases STAT3 activation in murine macrophages ${ }^{9-14}$. Lepr protein is present in bone marrow-derived macrophages from wild-type mice but not in Leprb mutant $d b / d b$ mice $^{10-12,15}$. In macrophages obtained from $d b / d b$ mice, $\mathrm{Li}$ et al. ${ }^{16}$ reported that expression of pro-inflammatory and anti-inflammatory cytokines is elevated, but Zykova et al. ${ }^{17}$ did not find differences in expression of pro-inflammatory cytokines in unstimulated conditions. However, characteristics of $d b / d b$ mouse macrophages may be confounded by the metabolic disturbances of the $d b /$ $d b$ model of complete leptin receptor signaling deficiency ${ }^{18,19}$.

Bone marrow transplantation studies involving $d b / d b$ and wild-type mice have yielded conflicting results regarding the effects of leptin signaling in cells of both the innate and adaptive immune systems on cytokine expression and glucose homeostasis ${ }^{20-23}$. Studies using Cre-lox methodology to diminish expression of the leptin receptor in cells of myeloid lineage yielded mild adverse effects on metabolic health, but both sexes were not consistently investigated and glucose metabolism was not always assessed. Mice deficient in all isoforms of the leptin receptor in myeloid cells generated using Lyz2Cre gained more weight on standard chow and had increased

\footnotetext{
${ }^{1}$ Department of Cellular and Physiological Sciences, Life Sciences Institute, University of British Columbia, 2350 Health Sciences Mall, Vancouver, BC V6T 1Z3, Canada. 'Department of Biochemistry and Molecular Biology, University of British Columbia, 2350 Health Sciences Mall, Vancouver, BC V6T 1Z3, Canada. ${ }^{3}$ Department of Surgery, University of British Columbia, 2775 Laurel Street, Vancouver, BC V5Z 1M9, Canada. ${ }^{4}$ School of Biomedical Engineering, University of British Columbia, 251-2222 Health Sciences Mall, Vancouver, BC V6T 1Z3, Canada. ${ }^{\boxplus}$ email: tim.kieffer@ubc.ca
} 
hepatic lipids, but glucose tolerance was not altered ${ }^{8}$. Any differences between male and female mice were not described. Using Lyz2Cre mice and floxed mice that allowed Leprb to be targeted, Scheller et al. ${ }^{24,25}$ also observed a tendency for greater weight gain in male mice, whereas body weight of female Leprb knockdown mice did not differ from controls up to 52 weeks of age. In addition, at 52 weeks of age females had inflammation in the liver. More recently, it was reported that the ability of macrophages from mice with myeloid cell-specific Leprb knockdown (generated using Lyz2Cre mice) to eradicate bacterial infection was diminished ${ }^{26}$. Interestingly, mice with myeloid cell-specific Leprb knockdown also had higher circulating levels of leptin vs. Cre ${ }^{+}$control mice at 8 weeks old, despite similar body weight; male and female mice were matched and pooled in study groups ${ }^{26}$. Moreover, blood glucose concentrations were similar between groups. Lastly, Gao et al. ${ }^{27}$ observed excess weight gain but normal glucose tolerance in male mice with diminished expression of Leprb in cells of myeloid lineage achieved with CX3cr1-Cre mice. The effects in female mice were not reported.

The above investigations of leptin action on cells of myeloid lineage focused on lipid metabolism, bone metabolism, defense against infection, body weight regulation, and neural physiology. Therefore, we performed various experiments to more thoroughly assess in vivo glucose metabolism in mice with diminished expression of Leprb in cells of myeloid lineage. We also generated mice that had Lepr expression restored selectively in cells of myeloid lineage and compared their glucose metabolism to that of mice with whole-body transcriptional blockade of Lepr. The latter mice have a phenotype similar to $d b / d b$ mice. To the best of our knowledge, a model of myeloid cell-specific Lepr reconstitution has not been reported in the literature. Lastly, since leptin is sexually dimorphic, we performed studies in male and female mice and report the results separately.

\section{Materials and methods}

Study design. We adhered to guidelines of the Canadian Council on Animal Care and the University of British Columbia Animal Care Committee approved all study procedures. Methods are reported according to ARRIVE guidelines. Homozygous Lyz2Cre+ mice (The Jackson Laboratory, Bar Harbor, ME, USA, Stock \#004781) were mated with C57BL/6 mice (The Jackson Laboratory) to give rise to hemizygous $\mathrm{Lyz}_{2} \mathrm{Cre}^{+}$mice that were subsequently used as breeders in our colonies. All mice used for studies were hemizygous for Cre. In the presence of a floxed gene, $\mathrm{Lyz}_{2} \mathrm{Cre}^{+}$mice have Cre-mediated excision specifically in myeloid cells ${ }^{28}$. Lyz2Cre mice are commonly used to knock down a gene in myeloid cells, which include macrophages, via Cre-lox methodology ${ }^{29-31}$. For the Lepr knockdown study, mice with myeloid cell-specific Lepr knockdown $\left(\right.$ Lyz2Cre $^{+}$eppr $^{\text {floxfflox }}$ ) and littermate controls (Flox controls, Lyz2Cre Lepr $^{\text {flox/flox; }}$; Cre controls, Lyz2Cre Lepr $^{+/+}$; wild-type controls, $L y z 2 \mathrm{Cre}^{-} \mathrm{Lepr}^{+/+}$) were created by starting off mating Lyz2Cre ${ }^{+}$mice with Leprflox/flox mice. Lep$r^{f l o x f f l o x}$ mice have loxP sites surrounding exon 17 of the leptin receptor gene and Cre-mediated excision causes a frameshift mutation and premature stop codon, thereby impeding expression of the long isoform of the leptin receptor $^{32-34}$. For the Lepr reconstitution study, Lyz2Cre ${ }^{+}$mice were mated with $L_{e p r^{\text {loxTB/+ }}}$ mice to create mice with myeloid cell-specific Lepr reconstitution $\left(L y z 2 C r e^{+} L e p r^{l o x T B / l o x T B}\right)$ and littermate controls, namely mice with global transcriptional blockade of the leptin receptor $\left(\right.$ Lyz2Cre $\left.\operatorname{Lepr}^{\text {loxTB/loxTB }}\right)$, Cre controls $\left(L y z 2 \mathrm{Cre}^{+} L_{e p r^{+/+}}\right)$ and wild-type controls $\left(\right.$ Lyz2Cre ${ }^{-}$Lepr $\left.^{+/+}\right)$. We have previously described the Leprflox/flox and Lepr ${ }^{\text {loxTB/+ }}$ mice used as breeders, including their background ${ }^{35}$. For the Lepr knockdown and Lepr reconstitution studies, control mice were littermate controls. Ear notches were collected for genotyping and primers used for genotyping are listed in "Supplementary Information S1". Mice had free access to water and food (Harlan diet \#2919 when breeding and Harlan diet \#2918 for maintenance) and were kept on a 12 h:12 h light-dark cycle (lights on at 7 a.m.).

Blood glucose measurements and plasma assays. Body weight was assessed, blood glucose was measured, and blood was collected after fasting for $4 \mathrm{~h}$, starting in the morning, unless stated otherwise. Blood was collected from the saphenous vein. OneTouch Verio glucometers (Life Scan, Burnaby, BC, Canada) were used to measure blood glucose concentrations for the fasting challenge experiments in the Lepr reconstitution study. For all other studies, OneTouch Ultra glucometers (Life Scan) were utilized to determine blood glucose concentrations. Values above or below the limits of detection (33.3 and $1.1 \mathrm{mM}$ ) were assigned values of 33.3 and $1.1 \mathrm{mM}$, respectively. Plasma glucose was determined with an in vitro glucose assay that utilizes hexokinase and glucose 6-phosphate dehydrogenase (Sekure Chemistry, Sekisui Diagnostics, Charlottetown, PEI, Canada). Plasma leptin was quantified with a mouse leptin ELISA (Crystal Chem, Downers Grove, IL, USA). A mouse insulin ultrasensitive ELISA (Alpco, Salem, NH, USA) was used for plasma samples from the knockdown study. For the reconstitution study, plasma insulin was measured with the Stellux Chemi Rodent Insulin ELISA (Alpco); plasma samples from Lyz2Cre Lepr $^{\text {loxTB/loxTB }}$ and $L y z 2 C r e^{-} L e p r^{\text {loxTB/loxTB }}$ mice were diluted 1:3, while plasma samples from $\mathrm{Lyz} 2 \mathrm{Cre}^{+} \mathrm{Lepr}^{+/+}$and $\mathrm{Lyz} 2 \mathrm{Cre}^{-} \mathrm{Lepr}^{+/+}$mice were run neat. Total and high molecular weight (HMW) adiponectin in plasma was quantified using an ELISA from Alpco. Plasma free fatty acids (FFAs) were quantified as previously described ${ }^{36}$.

Metabolic tests. For the Lepr knockdown study, insulin tolerances tests (ITTs) were performed after a $4 \mathrm{~h}$ morning fast in mice 18-21 weeks old. Insulin (Novolin ge Toronto, Novo Nordisk, Mississauga, ON, Canada) was injected i.p. at a dose of $0.75 \mathrm{U}$ per $\mathrm{kg}$ body weight for males and $0.5 \mathrm{U}$ per $\mathrm{kg}$ body weight for females. Oral glucose tolerance tests (OGTTs) involved administering 1.5 g glucose per kg body weight, using a $30 \%$ glucose solution, to mice 23-27 weeks old after a $4 \mathrm{~h}$ morning fast. For fasting challenge experiments, the start of fasting for mice was 5:30-6:30 pm and mice were 38-46 weeks old. Pyruvate tolerance tests (PTTs) were done in mice 42-55 weeks old following an overnight ( $16 \mathrm{~h}$ ) fast; sodium pyruvate (Fisher Scientific, Ottawa, ON, Canada) was dissolved in $0.9 \% \mathrm{NaCl}$ and administered i.p. at a dose of $2 \mathrm{~g}$ per $\mathrm{kg}$ body weight ${ }^{37}$.

For the Lepr reconstitution study, ITTs were performed in mice aged 9-13 weeks old after a $4 \mathrm{~h}$ morning fast. For male and female Cre $e^{+}$epr $r^{\text {loxTB/loxTB }}$ and $C r e^{-}$Lepr $^{\text {loxTB/loxTB }}$ mice, the insulin dose was $2 \mathrm{U}$ per kg body weight 
i.p. For male $\mathrm{Lyz} 2 \mathrm{Cre}^{+} \mathrm{Lepr}^{+/+}$and $\mathrm{Lyz2Cre} \mathrm{Lepr}^{+/+}$mice, the insulin dose was $0.75 \mathrm{U}$ per kg body weight i.p., while

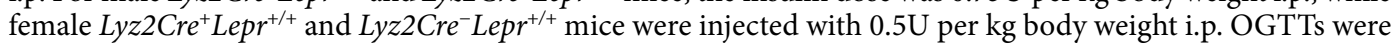
done in mice $25-26$ weeks old after an overnight $(16 \mathrm{~h})$ fast; all mice received the same dose of glucose $(1 \mathrm{~g}$ per $\mathrm{kg}$ body weight), but while a $50 \%$ glucose solution was used for $\mathrm{Cr}^{+} \mathrm{Lepr}^{\text {loxTB/loxTB }}$ and $C r e^{-} \mathrm{Lepr}^{\text {loxTB/loxTB }}$ mice, a $25 \%$ glucose solution was used for $\mathrm{Lyz}_{2} \mathrm{Cre}^{+} \mathrm{Lepr}^{+/+}$and $\mathrm{Lyz} 2 \mathrm{Cre}^{-} \mathrm{Lepr}^{+/+}$mice. Length of fast affects circulating glucose concentrations in obese mice. In order to start the OGTTs when circulating glucose concentrations were normal or near normal in males with Lepr reconstitution $\left(L y z 2 C r e^{+} L e p r^{\text {loxTB/loxTB }}\right)$, OGTTs were performed after an overnight fast. For fasting challenge experiments, fasting started at 5:30-6:30 pm and mice were 19-42 weeks old (equally distributed).

Assessment of Lepr flox recombination in bone marrow-derived macrophages. Bone mar-

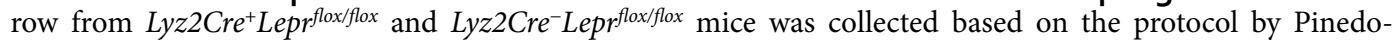
Torra et al. ${ }^{38}$. Unpolarized macrophages were obtained from bone marrow cells following 7 days of culture in uncharged plastic plates and media consisting of RPMI 1640, 10\% FBS, 20\% L929 cells conditioned medium, $100 \mathrm{U} / \mathrm{ml}$ penicillin/streptomycin, $1 \mathrm{X}$ non-essential amino acids, $1 \mathrm{mM}$ sodium pyruvate, and $0.05 \mathrm{mM}$ $\beta$-mercaptoethanol ${ }^{39}$. Cells were incubated at $37^{\circ} \mathrm{C}$ and $5 \% \mathrm{CO}_{2}$. DNA was extracted from unpolarized bone marrow-derived macrophages ${ }^{40}$. A qPCR assay was developed to quantify the extent of excision of the floxed

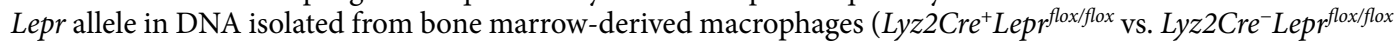
mice for each sex); the calculation of recombination using this assay as well as the primers and probes used have been described in a previous publication ${ }^{35}$. Briefly, primers were: LeprInt17-F, 5'CCTTTCCAGATAATGCCT GATAGA3'; LeprInt17-R, 5'GCACCACACTTAGCTCCAATA3'; LeprInt16-F, 5'GATCTCACACATACCAGA TCC3'; LeprInt16-R, 5'ATTTGATTCCACAAAGTGTTCC3'. Probes were: LeprInt17-FAM, 5' 56-FAM/TAG GGCGGA/ZEN/TGAACCAGCAAATGT/3IABkFQ; LeprInt16-HEX probe, 5'/5HEX/AGGAACTTCG/ZEN/ GAATAGGAACTTCGAATTCCTCGAGATC/3IABkFQ.

RT-qPCR. The RNeasy lipid tissue mini kit (Qiagen, Hilden, Germany) was used to extract RNA from perigonadal white adipose tissue samples of males and cDNA was subsequently obtained, as previously described ${ }^{35}$. Primer sequences: Arginase 1 (Arg1), Forward-5'TCTACATCACAGAAGAAATTTACAAGA3' and Reverse5'TTAGGTGGTTTAAGGTAGTCAGTCC3'; Interleukin 6 (Il6), Forward-5'CCAATTTCCAATGCTCTCCT3' and Reverse-5'ACCACAGTGAGGAATGTCCA3'; Interleukin 10 (Il10), Forward-5'GGAGCAGGTGAAGAG TGATTTTAA3' and Reverse-5'TGCAGGTGTTTTAGCTTTTCATTT3'; Tumor necrosis a (Tnf), Forward5'ACGGCATGGATCTCAAAGAC3' and Reverse-5'AGATAGCAAATCGGCTGACG3'. The reference transcript was peptidylpropyl isomerase A (Ppia); primer sequences were Forward-5'AGCTCTGAGCACTGGAGA GA3' and Reverse-5'GCCAGGACCTGTATGCTTTA3'. For samples without amplification, a Cq value of 39 was assigned. Calculation of relative expression (to wild-type controls for the Lepr reconstitution study and Flox controls for the Lepr knockdown study) was done with the Pfaffl equation.

Statistical analyses. Results are displayed as mean \pm SEM or box and whisker plots with individual points. Box and whisker plots have lines representing the median, 25th percentile, and 75th percentile, and whiskers representing the highest and lowest values. Statistical analyses were done using GraphPad Prism 8 and consisted of: (1) unpaired t-test when comparing two genotypes; (2) one-way ANOVA with Tukey's post-hoc test when comparing more than two genotypes, except for analyses of RT-qPCR results where Dunnett's post-hoc test was used due to small sample sizes; or (3) for parameters that changed over time, repeated measures two-way ANOVA. For the latter, when statistical significance was obtained for the main effect of genotype and/or interaction, comparison of genotypes was done at each time point using a post-hoc analysis, namely Bonferroni for two genotypes and Tukey for more than two genotypes. Analysis of plasma insulin concentrations during the OGTT in the Lepr reconstitution study was done with a mixed-effects model because: (1) values were missing at some timepoints for some mice due to difficulty in obtaining sufficient plasma from $C r e^{+} L e p r^{\text {loxTB/loxTB }}$ and

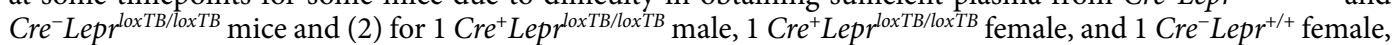
insulin ELISA results fell outside the standard curve. Tukey's post-hoc test was used when statistical significance was obtained for the main effect of genotype and/or interaction with the mixed-effects model. $\alpha=0.05$.

\section{Results}

We investigated whether reconstituting Lepr selectively in myeloid cells of mice with whole-body Lepr transcriptional blockade, which are characterized by obesity, hyperinsulinemia, and hyperleptinemia ${ }^{35}$, would alter glucose metabolism. Genotyping results from ear notch samples are shown in Supplementary Fig. S1. Among males, mice with myeloid cell-specific Lepr reconstitution $\left(\mathrm{Cr}^{+} \mathrm{Lepr}^{\text {loxTB/loxTB }}\right)$ and mice with global transcriptional blockade of Lepr $\left(C r e^{-}\right.$Lepr $\left.^{\text {loxTB/loxTB}}\right)$ had similar body weight to Cre controls $\left(C r e^{+} L_{e} p^{+/+}\right)$and wild-type controls $\left(\mathrm{Cre}^{-}\right.$Lep $\left.^{+/+}\right)$ at 3 weeks old (Fig. 1A). At 14 and 16 weeks old, male mice with myeloid cell-specific Lepr reconstitution and whole-body transcriptional blockade of Lepr were obese to a similar extent. Blood glucose was not significantly different at 3 weeks old between the 4 genotypes, but by 8 weeks of age, male mice with global transcriptional blockade of Lepr and myeloid cell-specific Lepr reconstitution were hyperglycemic (p < 0.05; Fig. 1B). Interestingly, at 14 and 16 weeks old, male mice with myeloid cell-specific Lepr reconstitution had reduced hyperglycemia compared to mice with global transcriptional blockade of $\operatorname{Lepr}(\mathrm{p}<0.05)$. Among females, body weight and blood glucose were comparable at 3 weeks old between the four genotypes, but at 8,14 , and 16 weeks old, mice with myeloid cell-specific Lepr reconstitution and mice with global transcriptional blockade of Lepr were similarly obese and hyperglycemic ( $\mathrm{p}<0.05$ vs. Cre controls and wild-type controls; Fig. 1C,D). 
A

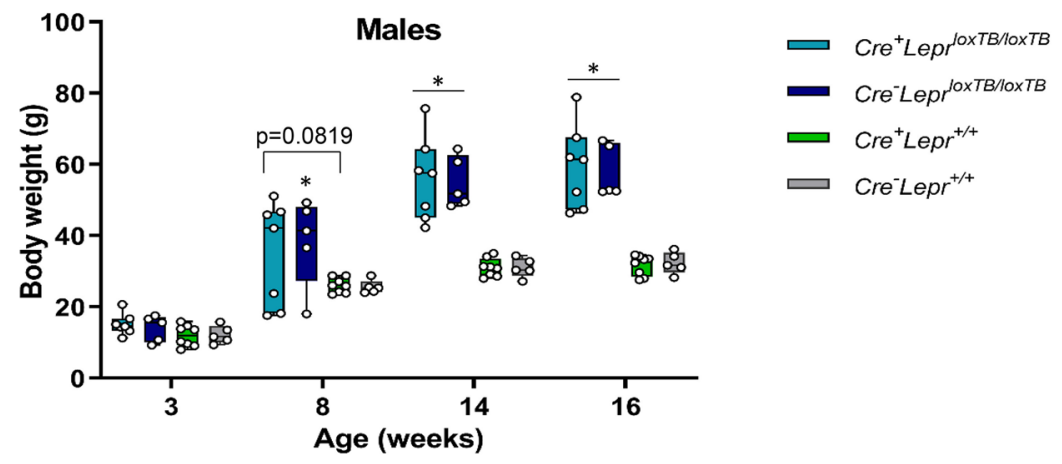

B

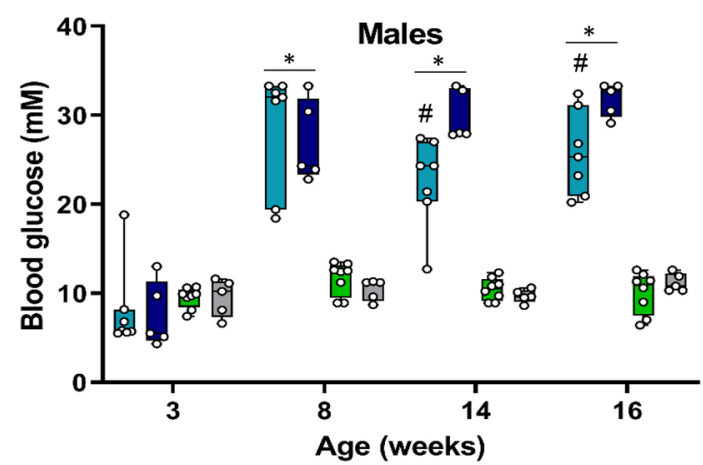

C

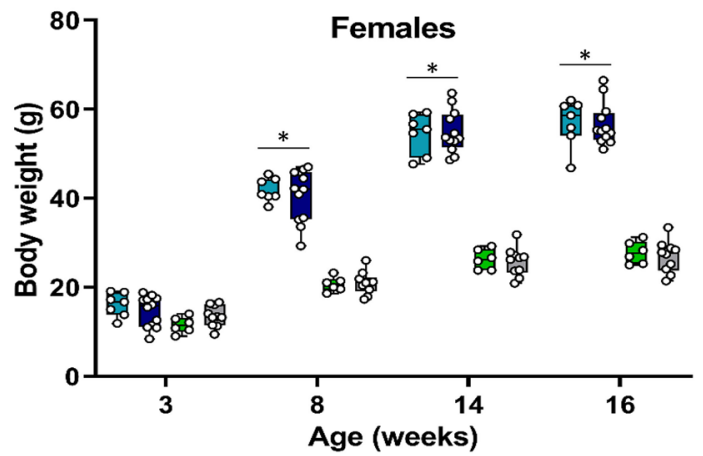

D

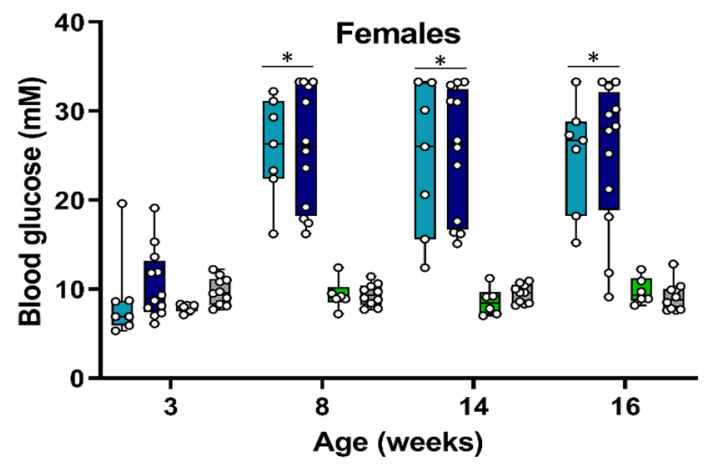

Figure 1. Body weight $(\mathbf{A}, \mathbf{C})$ and blood glucose $(\mathbf{B}, \mathbf{D})$ of mice from the Lepr reconstitution study at different ages. Parameters obtained after a $4 \mathrm{~h}$ fast. In (A) and (B), $\mathrm{n}=7$ for $C r e^{+} L_{\text {ep }} \mathrm{r}^{\text {loxTB } / \text { loxTB }}, \mathrm{n}=5$ for

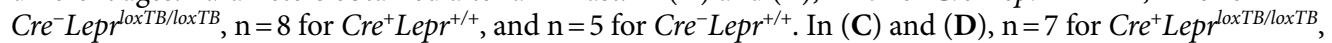
$\mathrm{n}=12$ for $\mathrm{Cre}^{-} \operatorname{Lepr}^{\text {loxTB/loxTB }}, \mathrm{n}=6$ for $\mathrm{Cre}^{+} \mathrm{Lepr}^{+/+}$, and $\mathrm{n}=10$ for $\mathrm{Cre}^{-} \mathrm{Lepr}^{+/+}$. Performed repeated measures two-way ANOVA with post-hoc analysis. ${ }^{\star} \mathrm{p}<0.05, \mathrm{Cre}^{+}$Lepr $^{\text {loxTB/loxTB }}$ and $C r e^{-} \operatorname{Lepr}^{\text {loxTB/loxTB}} \mathrm{vs.} \mathrm{Cre}^{+}$Lepr $^{+/+}$and $\mathrm{Cre}^{-} \mathrm{Lepr}^{+/+}$(except in A at 8 weeks old, where ${ }^{*} \mathrm{p}<0.05, \mathrm{Cre}^{-}$Lepr $^{\text {loxTB/loxTB }} \mathrm{vs.} \mathrm{Cre}^{+}$Lepr $^{+/+}$and Cre Lepr $^{+/+}$); ${ }^{\#} \mathrm{p}<0.05$ vs. Cre Lepr $^{\text {loxTB/loxTB }}$. Main effect of time $(\mathrm{p}<0.05)$ in $(\mathbf{A}-\mathbf{D})$. 
A

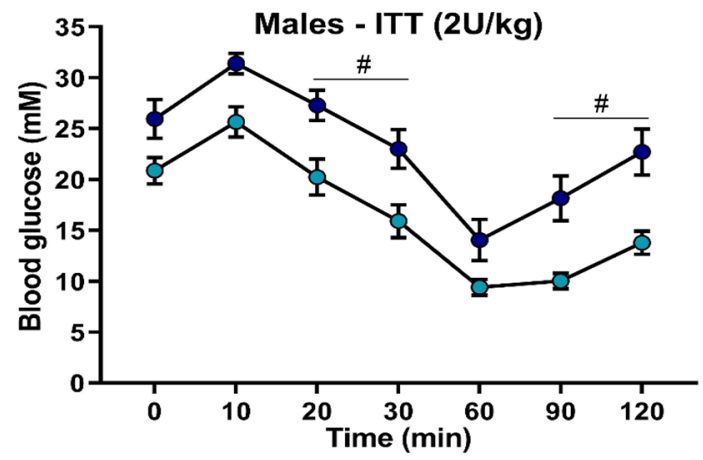

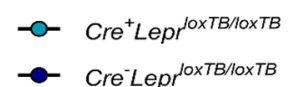

B

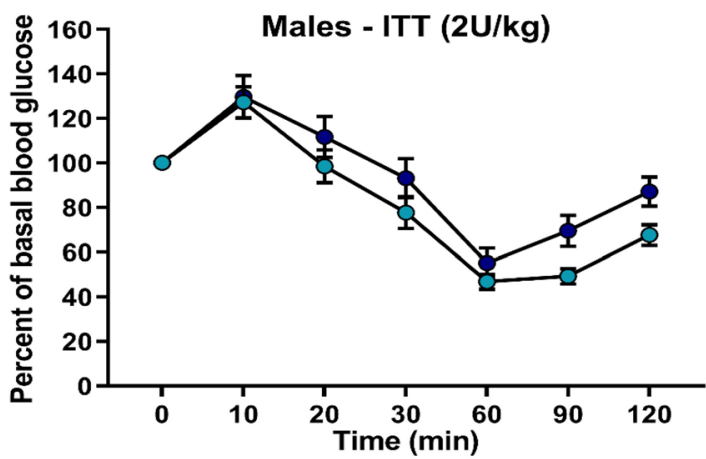

C

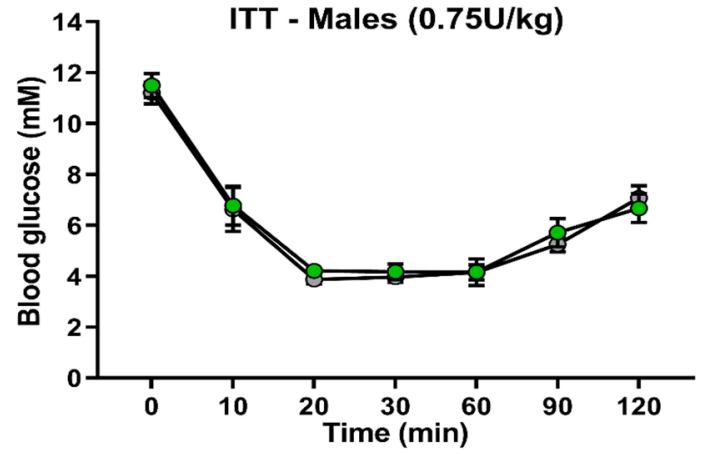

Figure 2. Insulin tolerance tests (ITTs) in male mice from the Lepr reconstitution study. In (A), the insulin dose was $2 \mathrm{U}$ per $\mathrm{kg}$ of body weight. In (B), blood glucose concentration of each mouse in (A) was normalized to its basal $(0 \mathrm{~min})$ blood glucose concentration. In (C), the insulin dose was $0.75 \mathrm{U}$ per kg of body weight. In (A) and (B), $\mathrm{n}=18$ for Cre ${ }^{+} \operatorname{Lepr}^{\text {loxTB/loxTB }}$ and $\mathrm{n}=14$ for $\mathrm{Cre}^{-} \operatorname{Lepr}^{\text {loxTB/loxTB }}$; in (C), $\mathrm{n}=15$ for $\mathrm{Cre}^{+} \operatorname{Lepr}^{+/+}$and $\mathrm{n}=11$ for $\mathrm{Cre}^{-} \mathrm{Lepr}^{+/+}$. Performed repeated measures two-way ANOVA with post-hoc analysis. ${ }^{*} \mathrm{p}<0.05$ vs. $\mathrm{Cre}^{-}$Lepr $^{\text {loxTB/loxTB}}$. Main effect of time $(\mathrm{p}<0.05)$ in $(\mathbf{A}-\mathbf{C})$.

Male mice with myeloid cell-specific Lepr reconstitution, aged 9-13 weeks old, had significantly lower blood glucose relative to Cre Lepr $^{\text {loxTB/loxTB }}$ mice at $20,30,90$, and $120 \mathrm{~min}$ of the ITT ( $<<0.05$; Fig. 2A), but there were no statistically significant differences between these two genotypes during the ITT when blood glucose concentrations were expressed as a percentage of basal $(0 \mathrm{~min})$ blood glucose concentrations (Fig. 2B). Male Cre controls and male wild-type controls had a similar blood glucose response during the ITT (Fig. 2C). Among females, the blood glucose profile during the ITT was similar in obese mice (Fig. 3A,B) as well as lean controls (Fig. 3C).

Male obese mice with and without Lepr reconstitution had impaired glucose tolerance during the OGTT at 25-26 weeks of age ( $\mathrm{p}<0.05$; Fig. 4A), but male mice with myeloid cell-specific Lepr reconstitution had moderately improved glucose tolerance compared to male mice with global transcriptional blockade of Lepr $(\mathrm{p}<0.05$ at 60, 90, and $120 \mathrm{~min}$; Fig. 4A). During the OGTT, male obese mice with and without Lepr reconstitution were hyperinsulinemic compared to Cre controls and wild-type controls (Fig. 4B). We have previously observed that $\mathrm{Cre}^{-}$Lepr $^{\text {loxTB/loxTB }}$ mice have a reduction in plasma insulin concentrations following an oral glucose challenge ${ }^{35}$. Female mice with Lepr reconstitution and global transcriptional blockade of Lepr were similarly glucose intolerant vs. Cre controls and wild-type controls ( $\mathrm{p}<0.05$; Fig. 4C). Female obese mice with and without Lepr 
A

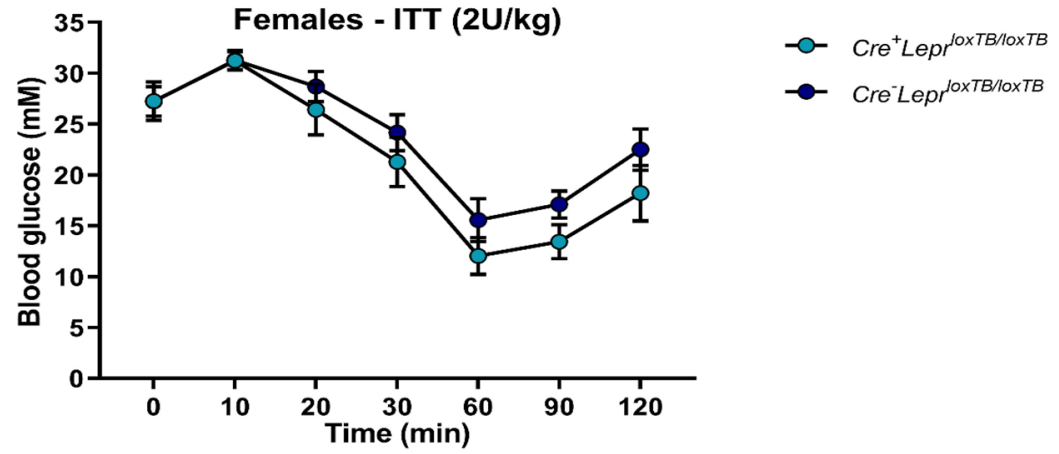

B

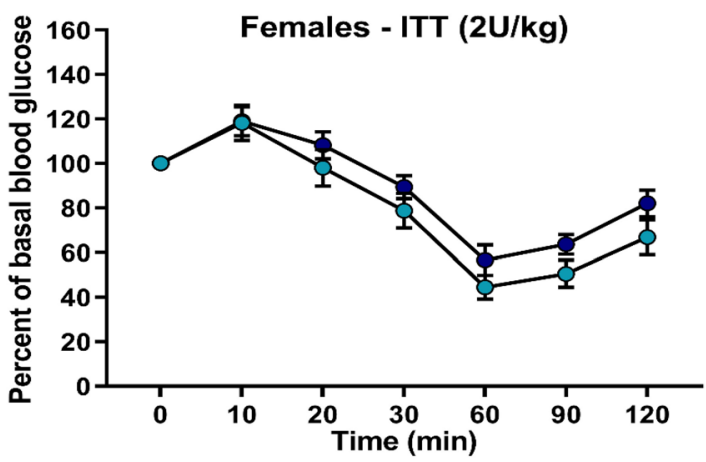

C

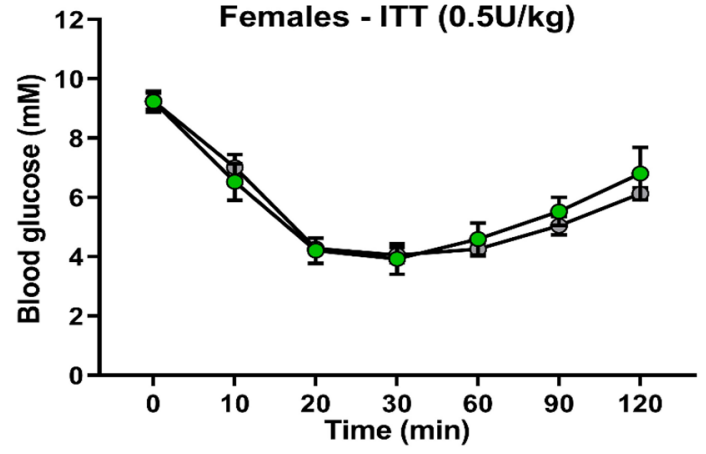

Figure 3. Insulin tolerance tests (ITTs) in female mice from the Lepr reconstitution study. In (A), the insulin dose was $2 \mathrm{U}$ per $\mathrm{kg}$ of body weight. In (B), blood glucose concentration of each mouse in (A) was normalized to its basal $(0 \mathrm{~min})$ blood glucose concentration. In $(\mathbf{C})$, the insulin dose was $0.5 \mathrm{U}$ per $\mathrm{kg}$ of body weight. In (A) and (B), $\mathrm{n}=8$ for Cre ${ }^{+} \operatorname{Lepr}^{\text {loxTB/loxTB }}$ and $\mathrm{n}=15$ for $\mathrm{Cre}^{-} \operatorname{Lepr}^{\text {loxTB/loxTB}}$; in (C), $\mathrm{n}=10$ for Cre $\mathrm{Lepr}^{+/+}$and $\mathrm{n}=11$ for $\mathrm{Cre}^{-} \mathrm{Lepr}^{+/+}$. Performed repeated measures two-way ANOVA with post-hoc analysis. Main effect of time $(\mathrm{p}<0.05)$ in $(\mathbf{A}-\mathbf{C})$.

reconstitution were hyperinsulinemic during the OGTT, but the female mice with Lepr reconstitution were less so (Fig. 4D).

Blood glucose was also determined after different fasting durations in older age mice. In males, hyperglycemia was lower in mice with myeloid cell-specific Lepr reconstitution vs. mice with global transcriptional blockade of Lepr at $0 \mathrm{~h}, 16 \mathrm{~h}$, and $24 \mathrm{~h}$ of fasting $(\mathrm{p}<0.05$; Fig. 5A). In females, there was a trend $(\mathrm{p}=0.0668)$ towards improved glycemia after $16 \mathrm{~h}$ of fasting in mice with myeloid cell-specific Lepr reconstitution vs. mice with whole-body transcriptional blockade of Lepr (Fig. 5C). Differences in body weight between mice with myeloid cell-specific Lepr reconstitution and global transcriptional blockade of Lepr compared to Cre controls and wild-type controls were retained throughout fasting $(\mathrm{p}<0.05$; Fig. 5B,D). Interestingly, male mice with global transcriptional blockade of Lepr were lighter than male mice with myeloid cell-specific Lepr reconstitution (Fig. $5 \mathrm{~B} ; \mathrm{p}<0.05$ ), which suggests that the former had poorer chronic glycemic control resulting in weight loss at an older age.

We also tested if circulating levels of the adipokine adiponectin differed between genotypes after a prolonged fast. Some bone marrow transplantation studies have reported improved adiponectin levels in mice with intact leptin signaling only in immune cells ${ }^{20,21}$. Adiponectin can reduce hepatic glucose production and expression 
A

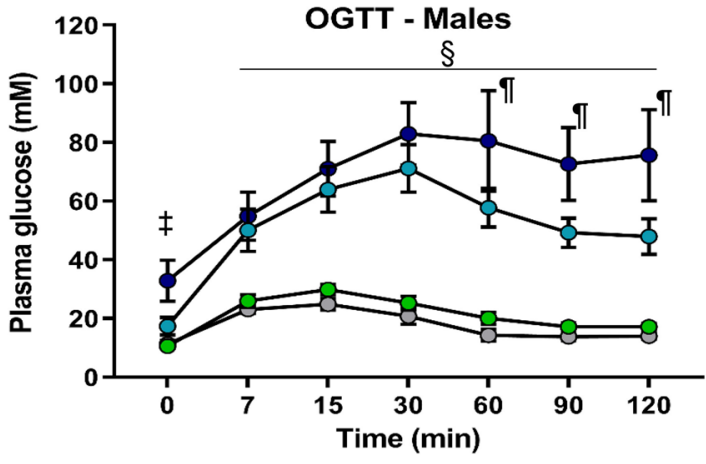

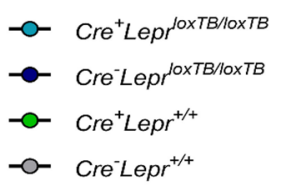

B

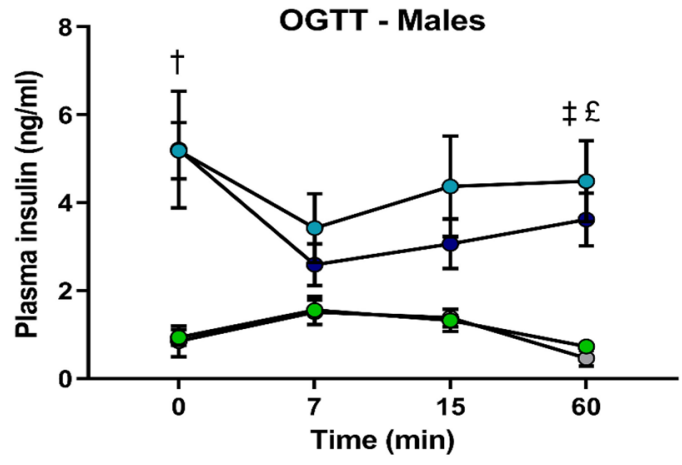

C

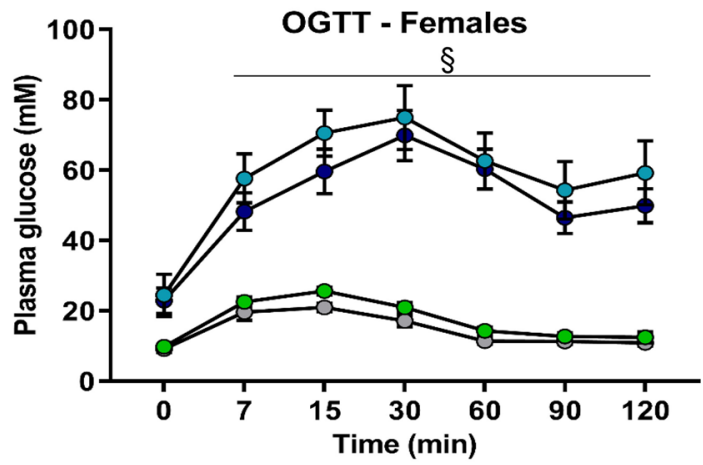

D

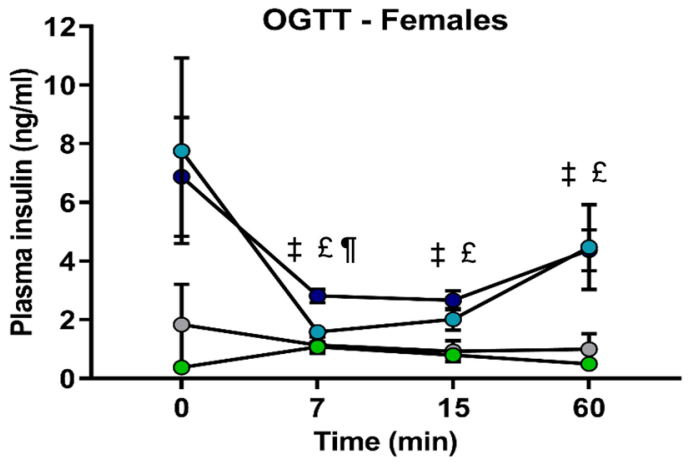

Figure 4. Plasma glucose $(\mathbf{A}, \mathbf{C})$ and plasma insulin $(\mathbf{B}, \mathbf{D})$ during oral glucose tolerance tests (OGTTs) in mice from the Lepr reconstitution study. In (A), $\mathrm{n}=6$ for $\mathrm{Cre}^{+} \operatorname{Lepr}^{\text {loxTB/loxTB }}, \mathrm{n}=5$ for $\mathrm{Cre}^{-} \operatorname{Lepr}^{\text {loxTB/loxTB }}, \mathrm{n}=9$ for $\mathrm{Cre}^{+} \mathrm{Lepr}^{+/+}$, and $\mathrm{n}=6$ for $\mathrm{Cre}^{-} \mathrm{Lepr}^{+/+}$. In (B), for Cre $\mathrm{Lepr}^{\text {loxTB/loxTB }}, \mathrm{n}=5$ at all timepoints, except at $\mathrm{t}=60 \mathrm{~min}$, where $\mathrm{n}=3$; for $\mathrm{Cre}^{-} \mathrm{Lepr}^{\text {loxTB/loxTB }}$, $\mathrm{n}=5$ at all timepoints, except at $\mathrm{t}=7 \mathrm{~min}$ and $\mathrm{t}=15 \mathrm{~min}$, where $\mathrm{n}=4$; for $\mathrm{Cre}^{+} \mathrm{Lepr}^{+/+}, \mathrm{n}=9$ at all timepoints; for $\mathrm{Cre}^{-} \mathrm{Lepr}^{+/+}$, $\mathrm{n}=5$ at all timepoints. In (C), $\mathrm{n}=6$ for $\mathrm{Cre}^{+} \operatorname{Lepr}^{\text {loxTB/loxTB }}, \mathrm{n}=9$ for $\mathrm{Cre}^{-} \operatorname{Lepr}^{\text {loxTB/loxTB }}, \mathrm{n}=8$ for Cre $\mathrm{Lepr}^{+/+}$, and $\mathrm{n}=9$ for $\mathrm{Cre}^{-} \mathrm{Lepr}^{+/+}$. In (D), for Cre $\mathrm{Lepr}^{\text {loxTB/loxTB }}, \mathrm{n}=6$ at all timepoints, except at $\mathrm{t}=0$ min, where $\mathrm{n}=5$, at $\mathrm{t}=7$ min, where $\mathrm{n}=4$, and $\mathrm{t}=15$ min, where $\mathrm{n}=5$; for Cre Lepr $^{\text {loxтв/loxTB }}, \mathrm{n}=8$ at all timepoints, except at $\mathrm{t}=7$ min, where $\mathrm{n}=6, \mathrm{t}=15$ min, where $\mathrm{n}=7$, and $\mathrm{t}=60 \mathrm{~min}$, where $\mathrm{n}=7$; for $\mathrm{Cre}^{+} \mathrm{Lepr}^{+/+}, \mathrm{n}=8$ at all timepoints, except at $\mathrm{t}=0 \mathrm{~min}$, where $\mathrm{n}=7$; for $\mathrm{Cre}^{-} \mathrm{Lepr}^{+/+}, \mathrm{n}=6$ at all timepoints, except at $\mathrm{t}=0 \mathrm{~min}$, where $\mathrm{n}=3$, and $\mathrm{t}=7 \mathrm{~min}$, where $\mathrm{n}=5$. In $(\mathbf{A})$ and $(\mathbf{C})$, repeated measures two-way ANOVA with post-hoc analysis was performed. In (B) and (D), a mixed-effects model with post-hoc analysis was carried out. ${ }^{8} \mathrm{p}<0.05$, $\mathrm{Cre}^{+}$LeproxTB/loxTB $^{\text {lond Cre }}{ }^{-}$Lepr $^{\text {loxTB/loxTB }}$ vs. Cre ${ }^{+} \mathrm{Lepr}^{+/+}$and $\mathrm{Cre}^{-} \mathrm{Lepr}^{+/+} ;{ }^{\dagger} \mathrm{p}<0.05, \mathrm{Cre}^{+} \mathrm{Lepr}^{\text {loxTB/loxTB}}$ vs. Cre $\mathrm{Lepr}^{+/+}$and

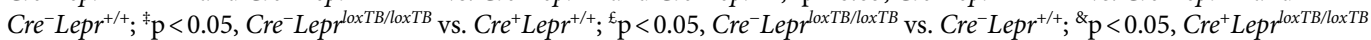
vs. $\mathrm{Cre}^{+} \operatorname{Lepr}^{+++} ;{ }^{9} \mathrm{p}<0.05 \mathrm{Cre}^{+} \operatorname{Lepr}^{\text {loxTB/loxTB }}$ vs. Cre Lepr $^{\text {loxTB/loxTB }}$. Main effect of time $(\mathrm{p}<0.05)$ in $(\mathbf{A}, \mathbf{C}, \mathbf{D})$. 
A

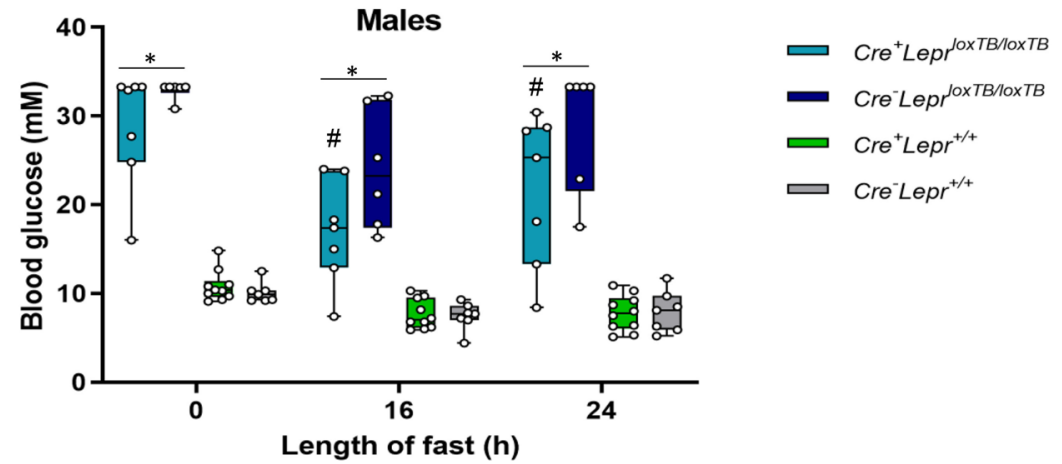

B

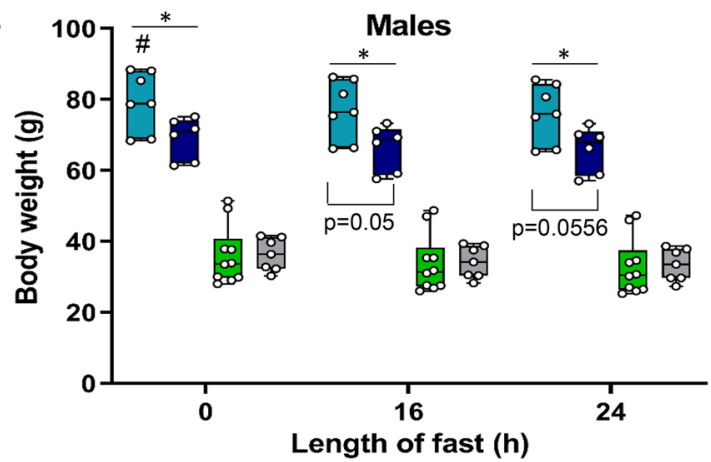

C
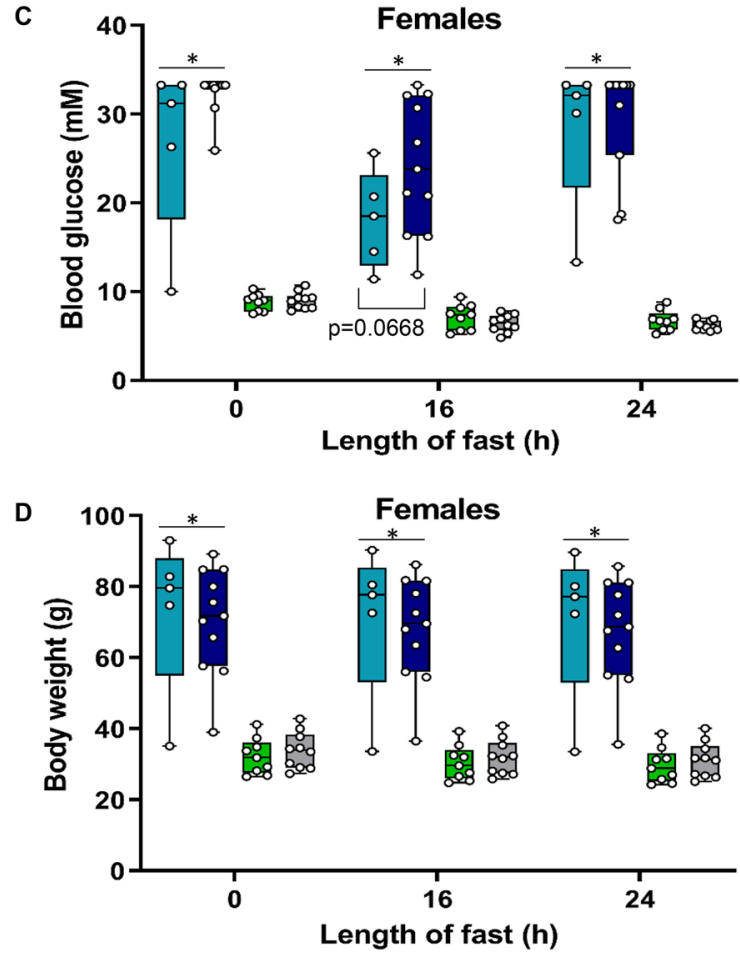

Figure 5. Blood glucose concentration $(\mathbf{A}, \mathbf{C})$ and body weight $(\mathbf{B}, \mathbf{D})$ of mice from the Lepr reconstitution study at different fasting times. In (A) and (B), $\mathrm{n}=7$ for $C r e^{+}$Lepr $^{\text {loxTB/loxTB }}, \mathrm{n}=6$ for Cre Lepr $^{\text {loxTB/loxTB }}, \mathrm{n}=10$ for $\mathrm{Cre}^{+} \mathrm{Lepr}^{+/+}$, and $\mathrm{n}=7$ for $\mathrm{Cre}^{-} \mathrm{Lepr}^{+/+}$. In (C) and (D), $\mathrm{n}=5$ for $\mathrm{Cre}^{+} \operatorname{Lepr}^{\text {loxTB/loxTB }}, \mathrm{n}=11$ for Cre Lepr $^{\text {loxTB/loxTB }}$, $\mathrm{n}=9$ for $\mathrm{Cre}^{+} \mathrm{Lepr}^{+/+}$, and $\mathrm{n}=10$ for $\mathrm{Cre}^{-} \mathrm{Lepr}^{+/+}$. Performed repeated measures two-way ANOVA with posthoc analysis. ${ }^{*} \mathrm{p}<0.05, C r e^{+} L_{e p r} r^{\text {loxTB/loxTB }}$ and $C r e^{-}$Lepr $^{\text {loxTB } / \text { loxTB }}$ vs. Cre ${ }^{+}$Lepr $^{+/+}$and $C r e^{-}$Lepr $^{+/+} ;{ }^{*} \mathrm{p}<0.05$ vs. Cre $e^{-}$Lepr $r^{\text {loxTB/loxTB }}$. Main effect of time $(\mathrm{p}<0.05)$ in $(\mathbf{A}-\mathbf{D})$. 
A

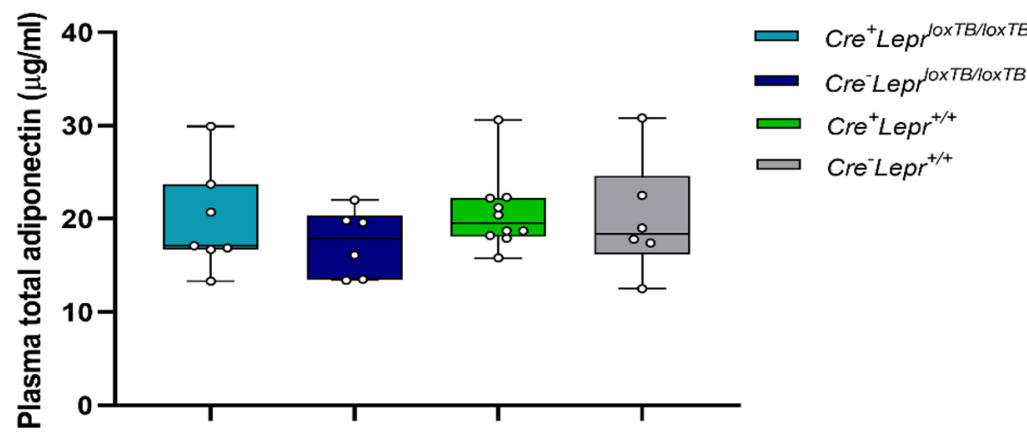

B

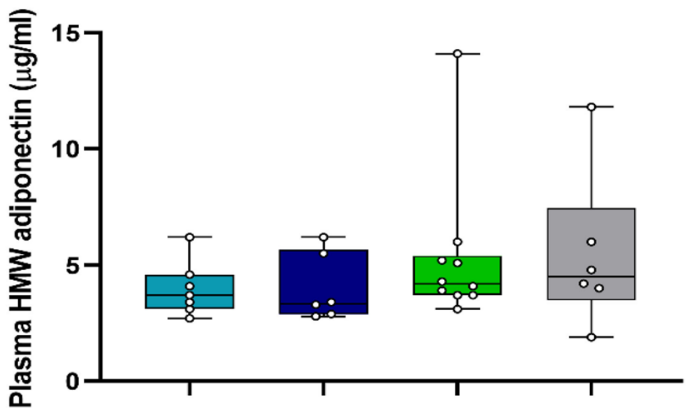

C

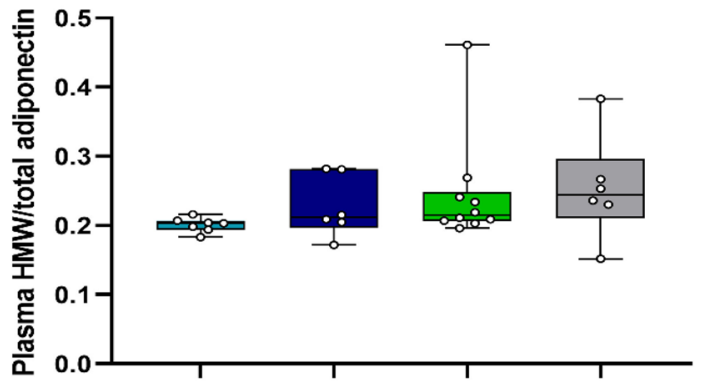

Figure 6. Concentration of total adiponectin (A), concentration of high molecular weight (HMW) adiponectin (B), and ratio of HMW to total adiponectin (C) in plasma obtained from male mice in the Lepr reconstitution study after a $16 \mathrm{~h}$ fast. In (A-C), $\mathrm{n}=7$ for $C r e^{+} \operatorname{Lepr}^{\text {loxTB/loxTB }}, \mathrm{n}=6$ for $\mathrm{Cre}^{-} \operatorname{Lepr}^{\text {loxTB/loxTB }}, \mathrm{n}=10$ for $\mathrm{Cre}^{+} \mathrm{Lepr}^{+/+}$, and $\mathrm{n}=6$ for $\mathrm{Cre}^{-} \mathrm{Lepr}^{+/+}$. Performed one-way ANOVA with Tukey's post-hoc test.

the decrease in blood glucose concentration in males with Lepr reconstitution after a prolonged fast suggests that these mice have reduced hepatic glucose production. We found that plasma adiponectin levels were not significantly different among male mice in the Lepr reconstitution study after a $16 \mathrm{~h}$ fast (Fig. 6).

Recombination in bone marrow-derived macrophages from $\mathrm{Lyz} 2 \mathrm{Cre} \mathrm{C}^{+} \mathrm{ep} \mathrm{r}^{\text {flox/flox }}$ mice was substantial, approximately 75\% (Fig. 7A). Genotyping results from ear notch samples are in Supplementary Fig. S2. Among males and females, there were no statistically significant differences in body weight, blood glucose, and plasma leptin, insulin and FFAs between mice with myeloid cell-specific Lepr knockdown and controls (Figs. 7B-E and 8). There were also no statistically significant differences during the ITT between mice with Lepr knockdown and controls (Fig. 9A,B). Results for the OGTT and blood glucose at different fasting times were similar between mice with Lepr knockdown and controls (Figs. 9C,D and 10A,B). A PTT was performed after an overnight fast to assess gluconeogenic flux. Blood glucose concentrations were similar between genotypes throughout the PTT in males and females (Fig. 10C,D). Hence, we did not detect any alterations in the phenotype of mice with myeloid-cell specific Lepr knockdown, which were characterized by normal weight as well as normal levels of circulating insulin and leptin.

Adipose tissue cytokine expression was assessed to determine if alterations in pro-inflammatory (Tnf and Il6) and anti-inflammatory (Arg1 and Il10) gene expression were associated with improvements in glycemic control in males with myeloid cell-specific Lepr reconstitution. Compared to wild-type controls, there were no statistically significant differences in Tnf, Il6, and Arg1 expression (Fig. 11A-C), but there was a trend for Il10 expression to be higher in mice with myeloid-cell specific Lepr reconstitution ( $\mathrm{p}=0.0774$; Fig. 11D). To complement these determinations in the Lepr reconstitution colony, expression of pro-inflammatory and anti-inflammatory 

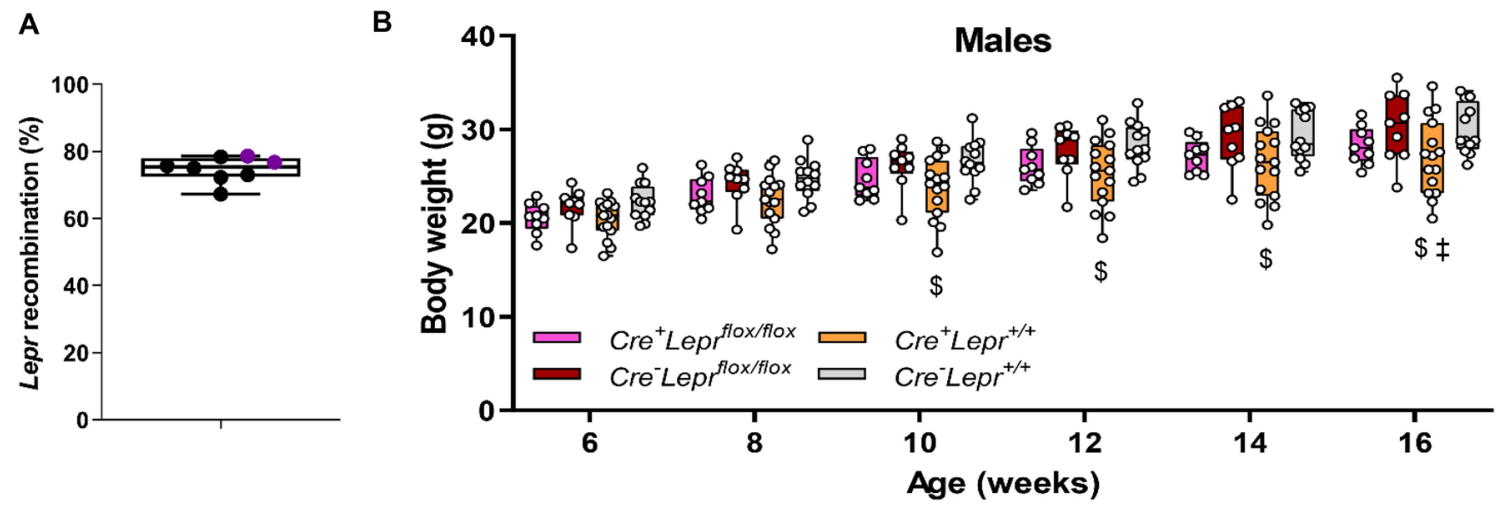

C

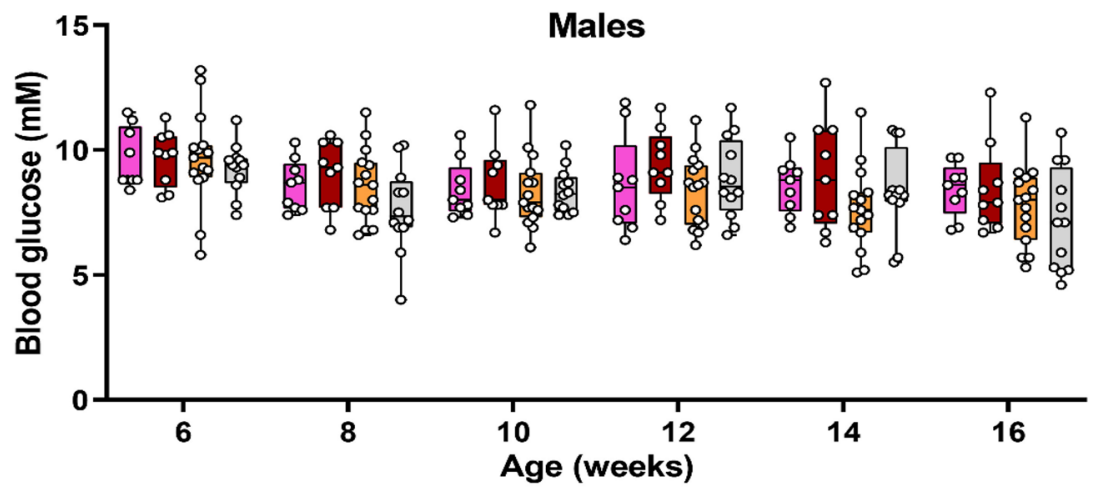

D

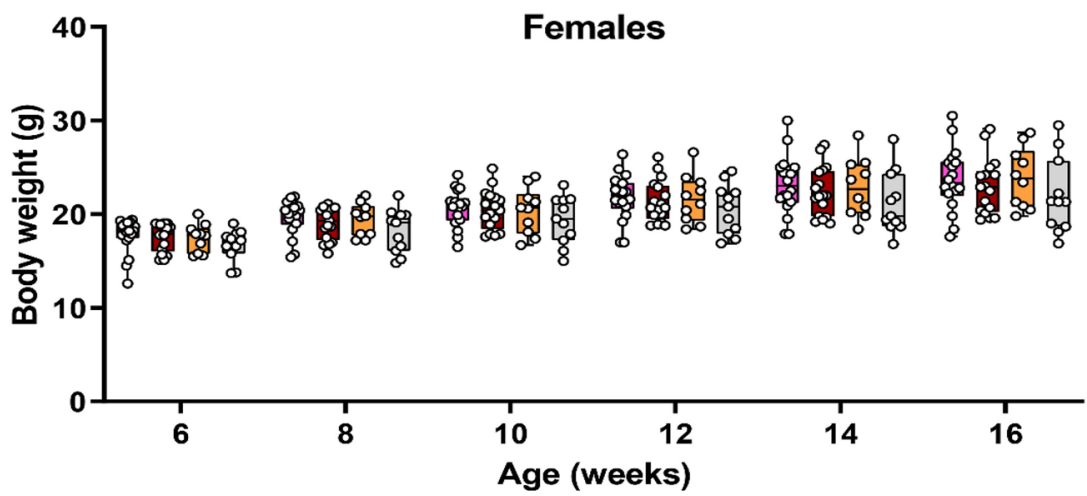

E

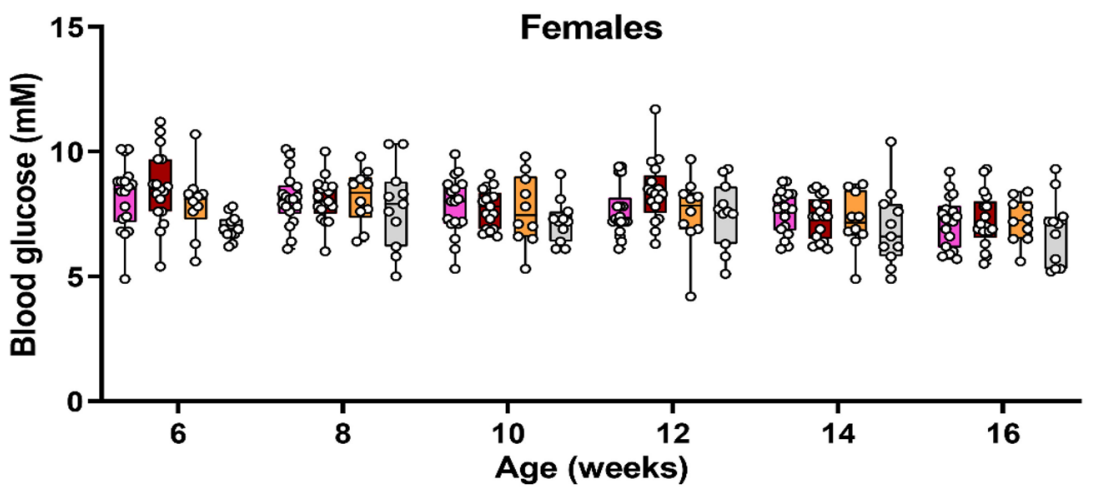

Figure 7. Recombination in bone marrow-derived macrophages of mice from the Lepr knockdown study; male mice are represented by black circles and female mice are represented by purple circles $(\mathbf{A})$. Body weight $(\mathbf{B}, \mathbf{D})$ and blood glucose (C, E) of mice from the Lepr knockdown study at different ages; parameters obtained after

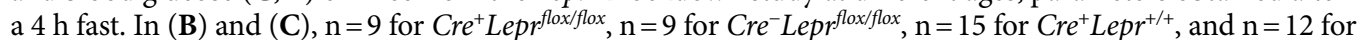
$\mathrm{Cre}^{-} \operatorname{Lepr}^{+/+}$. In (D) and (E), $\mathrm{n}=18$ for Cre ${ }^{+} \operatorname{Lepr}^{\text {flox/flox }}, \mathrm{n}=17$ for Cre ${ }^{-} \operatorname{Lepr}^{\text {flox/flox }}, \mathrm{n}=10$ for $\mathrm{Cre}^{+} \operatorname{Lepr}^{+/+}$, and $\mathrm{n}=11$ for $\mathrm{Cre}^{-} \mathrm{Lepr}^{+/+}$. Performed repeated measures two-way ANOVA with post-hoc analysis in $(\mathbf{B}-\mathbf{E}) .{ }^{\$} \mathrm{p}<0.05$, $\mathrm{Cre}^{+} \mathrm{Lepr}^{+/+}$vs. Cre Lepr $^{+/+} ;{ }^{ \pm} \mathrm{p}<0.05, \mathrm{Cre}^{-}$Lepr $^{f l o x / f l o x}$ vs. Cre ${ }^{+} \operatorname{Lepr}^{+/+}$. Main effect of time $(\mathrm{p}<0.05)$ in $(\mathbf{B}-\mathbf{E})$. 
A

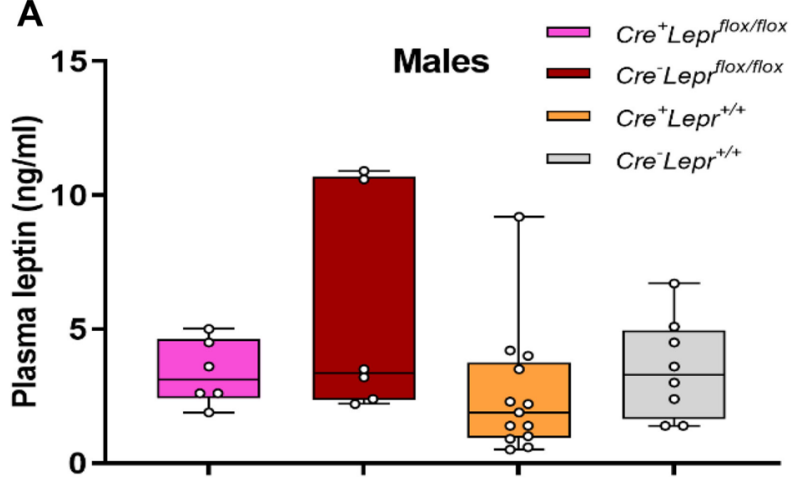

C

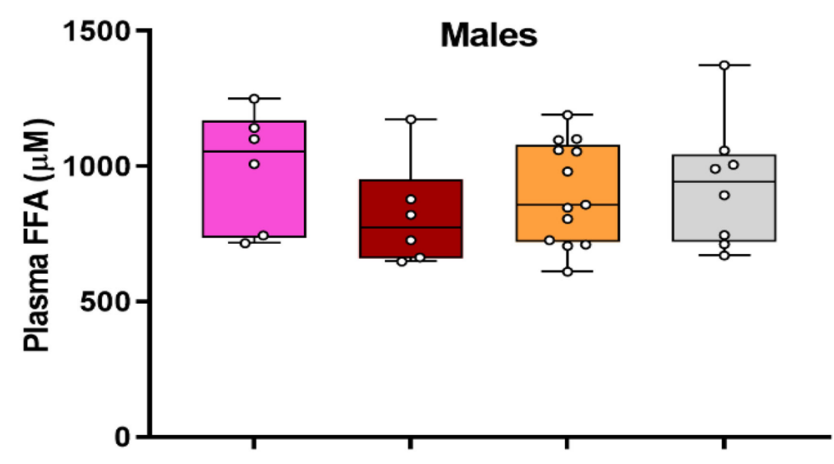

E

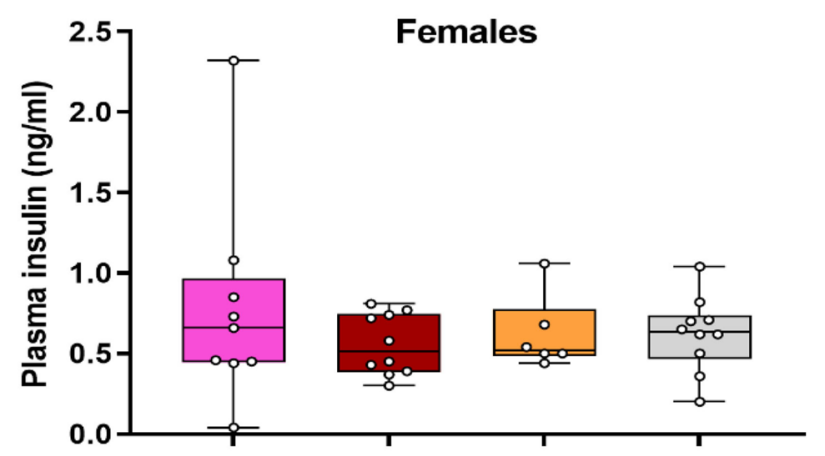

B

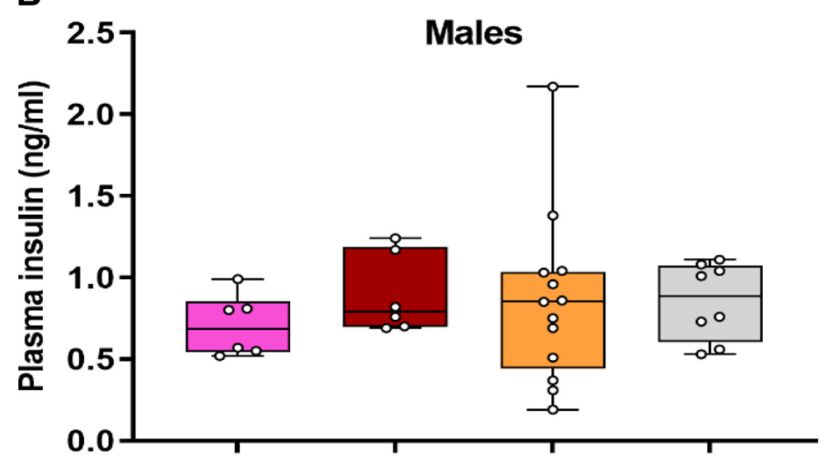

D

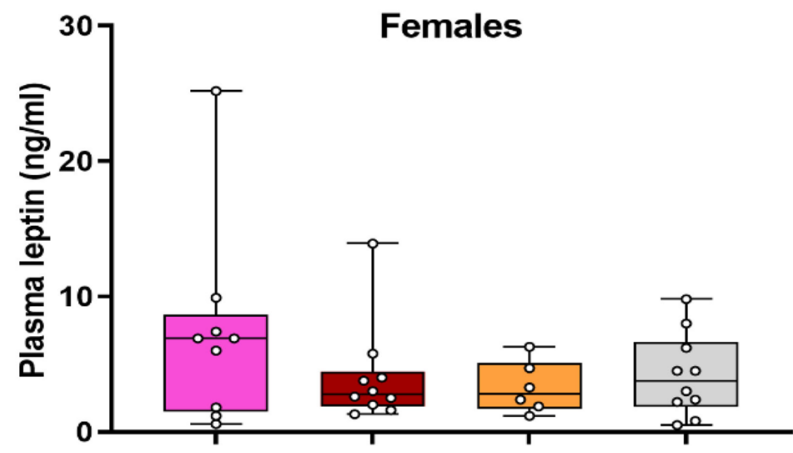

$\mathbf{F}$

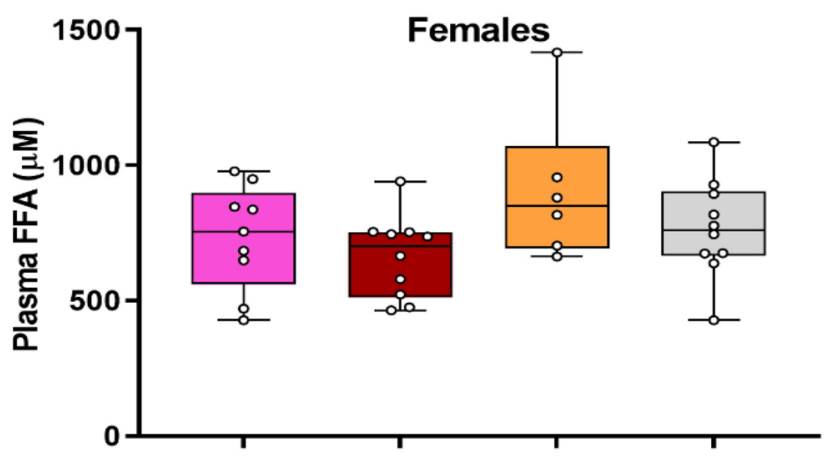

Figure 8. Plasma leptin (A, D), insulin (B, E), and free fatty acids (FFA) (C, F) of 12 week old mice from the Lepr knockdown study. Parameters obtained after $4 \mathrm{~h}$ fast. For males, $\mathrm{n}=6$ for $\mathrm{Cre}^{+}$Lepr $^{\text {flox } f f l o x}, \mathrm{n}=6$ for

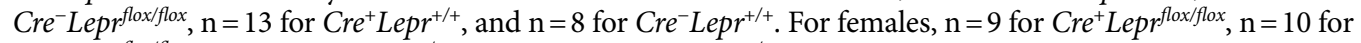
$\mathrm{Cre}^{-}$Lepr $^{f l o x} / f \mathrm{lox}, \mathrm{n}=6$ for $\mathrm{Cre}^{+} \mathrm{Lepr}^{++}$, and $\mathrm{n}=10$ for $\mathrm{Cre}^{-} \mathrm{Lepr}^{+/+}$. Performed one-way ANOVA with Tukey's posthoc test.

cytokines was also assessed in adipose tissue of males from the Lepr knockdown colony (Fig. 11E-H). Adipose tissue Il6 mRNA was significantly decreased in mice with myeloid cell-specific Lepr knockdown relative to controls ( $<<0.05$; Fig. 11F).

\section{Discussion}

We found that male mice with myeloid cell-specific Lepr reconstitution have diminished hyperglycemia in an age-dependent manner as well as better glucose tolerance compared to mice with whole-body transcriptional blockade of Lepr. Female mice with myeloid cell-specific Lepr reconstitution did not have ameliorated glucose metabolism, but there was a trend towards reduced hyperglycemia after a prolonged $(16 \mathrm{~h})$ fast. Reconstitution of Lepr did not significantly alter insulin sensitivity. The improved glycemic control in males with myeloid cell-specific Lepr reconstitution was associated with a trend for increased expression of the anti-inflammatory cytokine Il10 in adipose tissue. We also found that male and female mice with myeloid cell-specific Lepr knockdown had similar body weight, blood glucose, plasma parameters, insulin sensitivity, and glucose tolerance to 
A

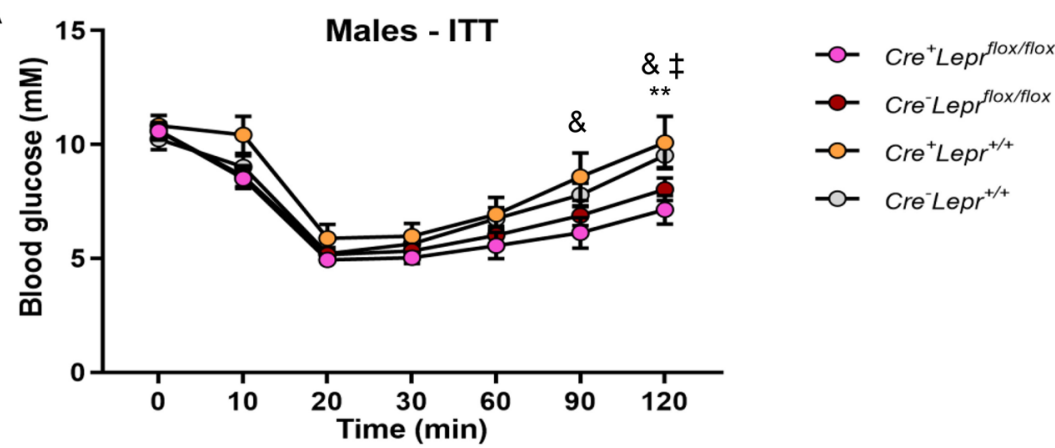

B

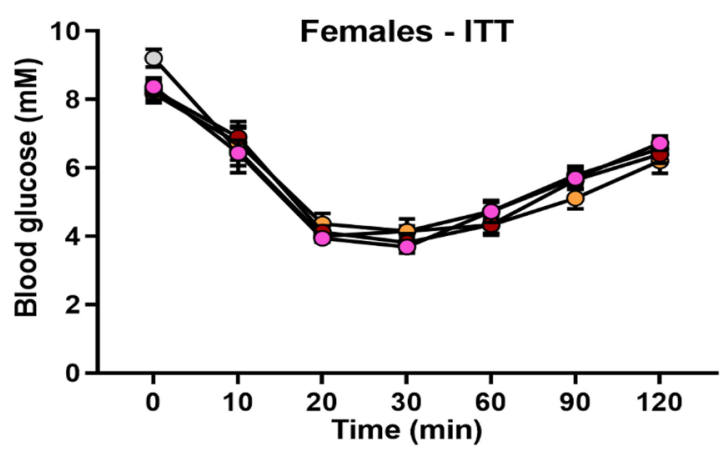

C

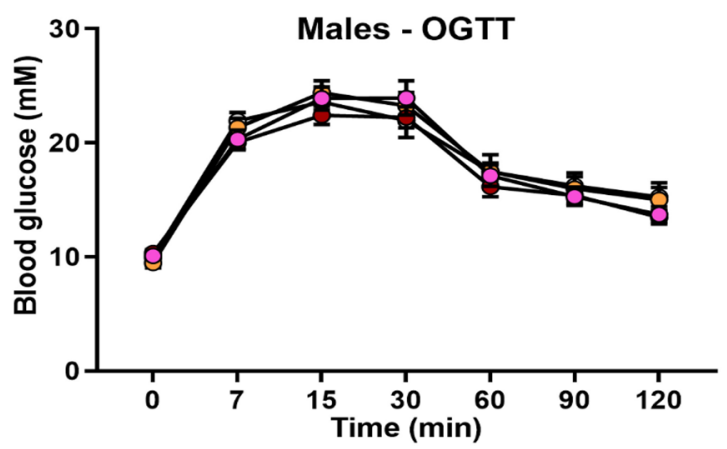

D

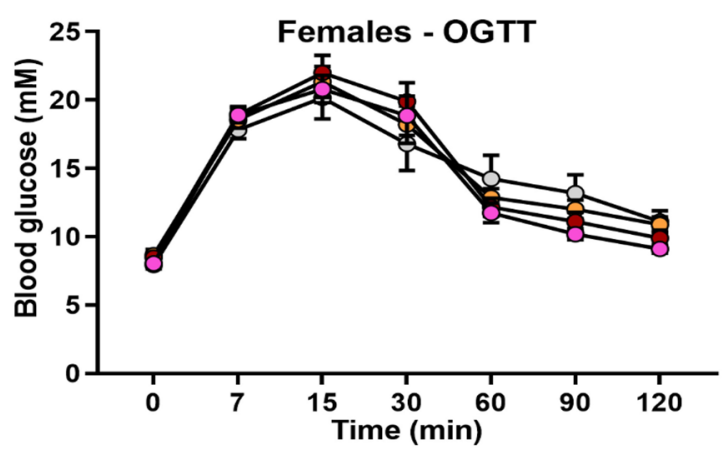

Figure 9. Insulin tolerance tests (ITTs) (A, B) and oral glucose tolerance tests (OGTTs) (C, D) in mice from the Lepr knockdown study. In (A), $\mathrm{n}=18$ for Cre $\operatorname{Lepr}^{\text {flox/flox }}, \mathrm{n}=20$ for $\mathrm{Cre}^{-} \operatorname{Lepr}^{\text {flox/flox }}, \mathrm{n}=12$ for $\mathrm{Cre}^{+} \mathrm{Lepr}^{+/+}$, and $\mathrm{n}=13$ for $\mathrm{Cre}^{-} \mathrm{Lepr}^{+/+}$. In (B), $\mathrm{n}=20$ for Cre ${ }^{+} \operatorname{Lepr}^{\text {flox/flox }}, \mathrm{n}=17$ for Cre $\mathrm{Lepr}^{\text {flox } / f l o x}, \mathrm{n}=9$ for Cre ${ }^{+} \operatorname{Lepr}^{+/+}$, and $\mathrm{n}=8$ for $\mathrm{Cre}^{-} \operatorname{Lepr}^{+/+}$. In $(\mathbf{C}), \mathrm{n}=15$ for Cre ${ }^{+} \operatorname{Lepr}^{\text {flox/flox }}, \mathrm{n}=18$ for Cre $\operatorname{Lepr}^{-10 x / f l o x}, \mathrm{n}=11$ for Cre ${ }^{+} \operatorname{Lepr}^{+/+}$, and $\mathrm{n}=12$ for $\mathrm{Cre}^{-} \mathrm{Lepr}^{+/+}$. In (D), $\mathrm{n}=20$ for Cre $\mathrm{Lepr}^{\text {floxfflox }}, \mathrm{n}=16$ for $\mathrm{Cre}^{-} \mathrm{Lepr}^{\text {floxfflox }}, \mathrm{n}=9$ for $\mathrm{Cre}^{+} \mathrm{Lepr}^{+/+}$, and $\mathrm{n}=8$ for $\mathrm{Cre}^{-} \mathrm{Lepr}^{+/+}$. Performed repeated measures two-way ANOVA with post-hoc analysis. ${ }^{\ddagger} \mathrm{p}<0.05, \mathrm{Cre}^{-} \mathrm{Lepr} \mathrm{flox}^{f / f l o x}$ vs. $C r e^{+}$Lepr $^{+/+} ;{ }^{\&} \mathrm{p}<0.05, \mathrm{Cre}^{+}$Lepr flox/flox vs. Cre Lepr $^{+/+} ;{ }^{* *} \mathrm{p}<0.05, \mathrm{Cre}^{+}$Lepr $^{\text {flox/flox }}$ vs. Cre $\mathrm{Lepr}^{+/+}$. Main effect of time $(\mathrm{p}<0.05)$ in $(\mathbf{A}-\mathbf{D})$. 
A

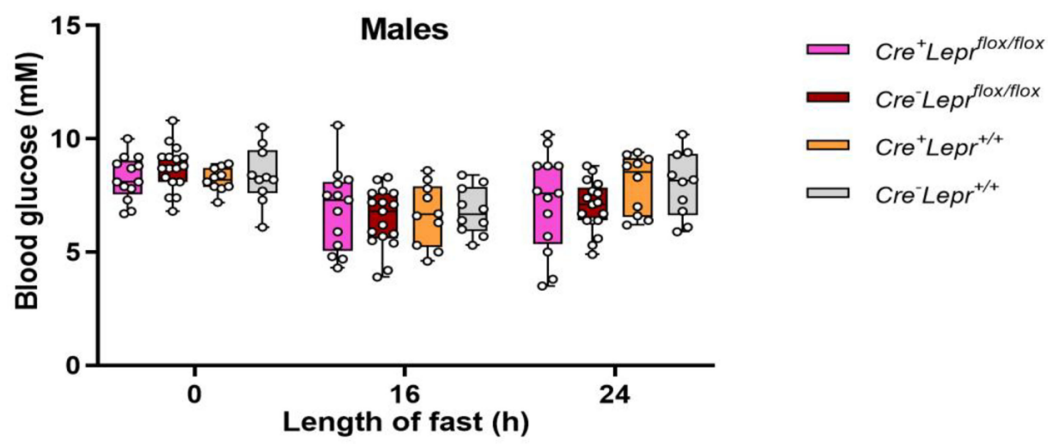

B

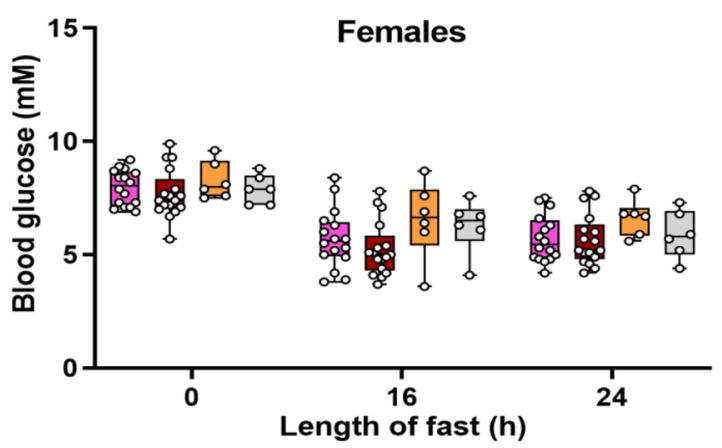

C

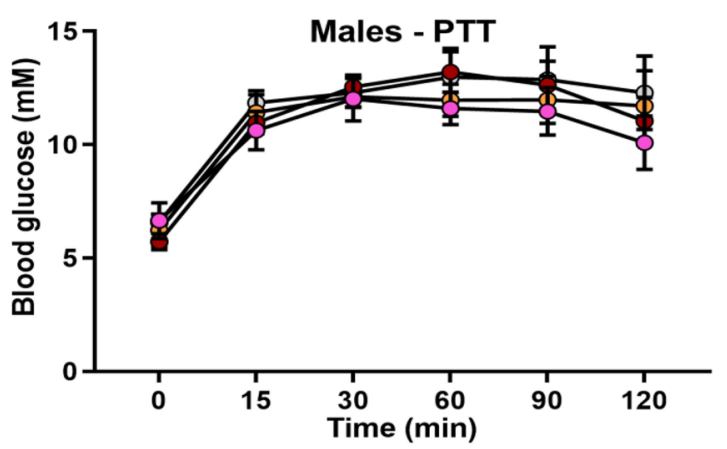

D

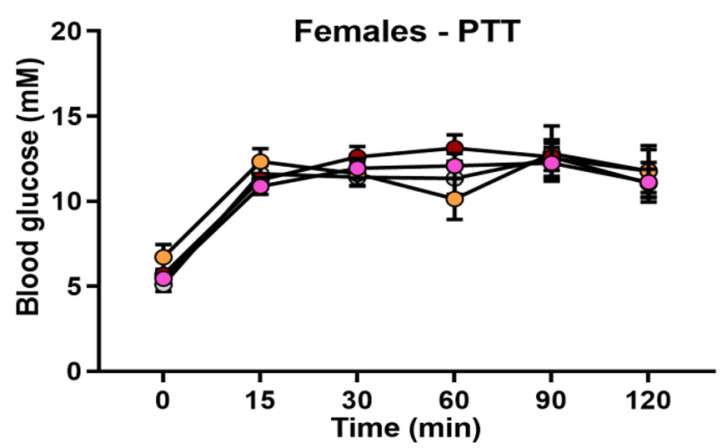

Figure 10. Blood glucose at different fasting times $(\mathbf{A}, \mathbf{B})$ and pyruvate tolerance tests $(\mathrm{PTTs})(\mathbf{C}, \mathbf{D})$ in mice from the Lepr knockdown study. In (A), $\mathrm{n}=13$ for Cre $e^{+}$Lepr flox/flox $_{\mathrm{n}} \mathrm{n}=17$ for Cre Lepr $^{\text {flox/flox }}, \mathrm{n}=10$ for $\mathrm{Cre}^{+} \mathrm{Lepr}^{+/+}$, and $\mathrm{n}=10$ for $\mathrm{Cre}^{-} \mathrm{Lepr}^{+/+}$. In (B), $\mathrm{n}=16$ for $\mathrm{Cre}^{+} \mathrm{Lepr}_{\text {flox/flox }}, \mathrm{n}=17$ for Cre $\mathrm{Lepr}^{\text {flox/flox }}, \mathrm{n}=6$ for $\mathrm{Cre}^{+}$Lepr $^{+/+}$, and $\mathrm{n}=6$ for $\mathrm{Cre}^{-} \operatorname{Lepr}^{+/+}$. In (C), $\mathrm{n}=13$ for Cre ${ }^{+}$Lepr $^{\text {flox/flox }}, \mathrm{n}=17$ for Cre ${ }^{-}$Lepr flox/flox, $\mathrm{n}=8$ for $\mathrm{Cre}^{+} \mathrm{Lepr}^{+/+}$, and $\mathrm{n}=9$ for Cre $\mathrm{Lepr}^{+/+}$. In (D), $\mathrm{n}=16$ for Cre $\mathrm{Lepr}^{\text {flox/flox }}, \mathrm{n}=17$ for Cre Lepr flox/flox $_{\mathrm{n}} \mathrm{n}=5$ for $\mathrm{Cre}^{+} \mathrm{Lepr}^{+/+}$, and $\mathrm{n}=6$ for $\mathrm{Cre}^{-} \mathrm{Lepr}^{+/+}$. Performed repeated measures two-way ANOVA with post-hoc analysis. Main effect of time $(\mathrm{p}<0.05)$ in $(\mathbf{A}-\mathbf{D})$. 
A

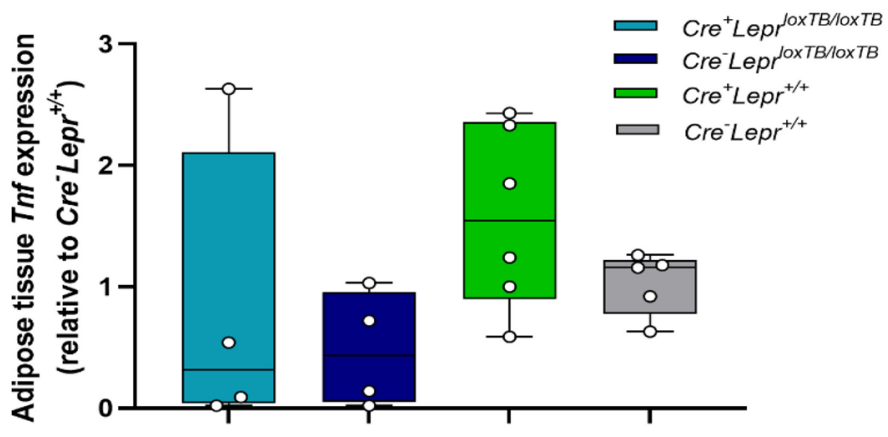

B

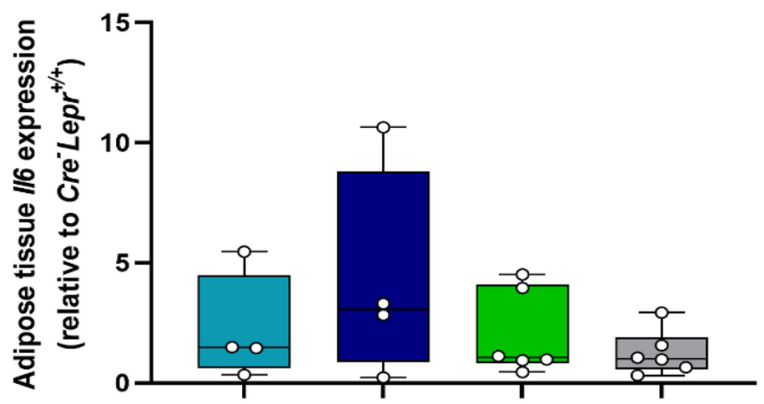

。

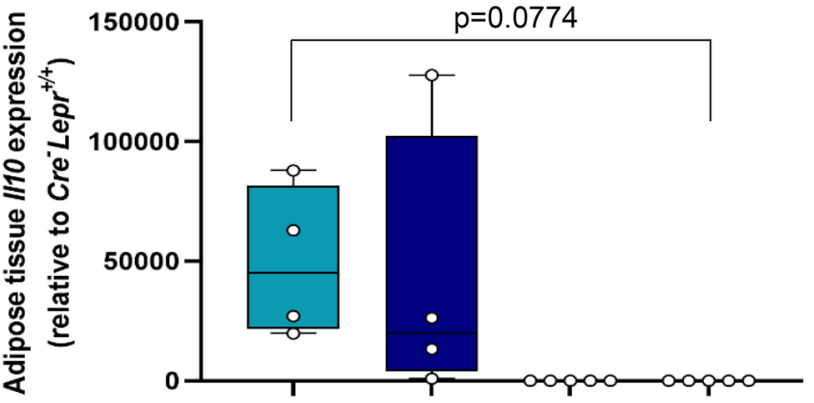

F

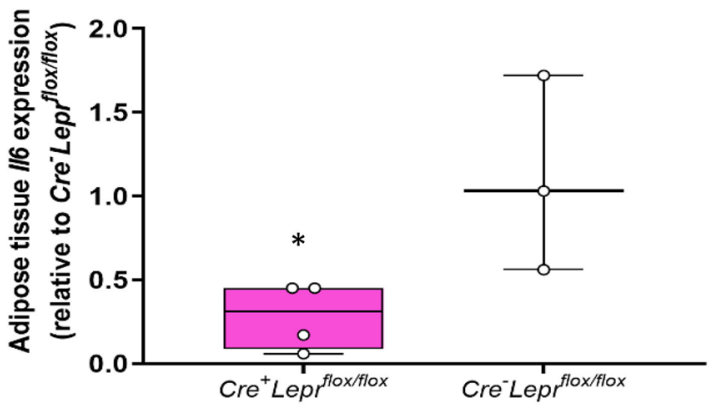

H

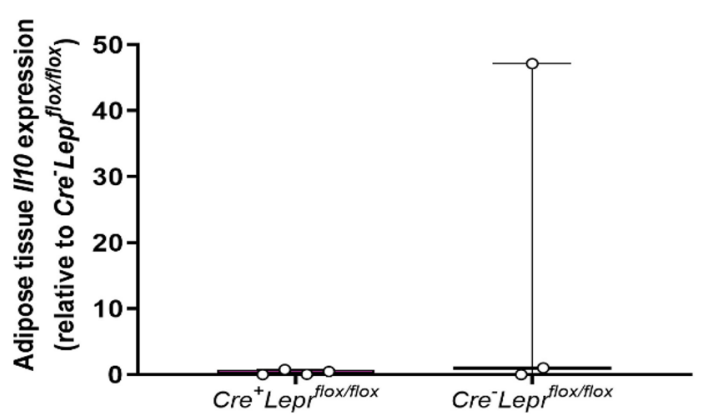

Figure 11. Adipose tissue pro- and anti-inflammatory cytokine expression assessed by RT-qPCR in males from the Lepr reconstitution and Lepr knockdown studies. In (A), $\mathrm{n}=4$ for $\mathrm{Cre}^{+}$Lepr $^{\text {loxTB/loxTB }}, \mathrm{n}=4$ for

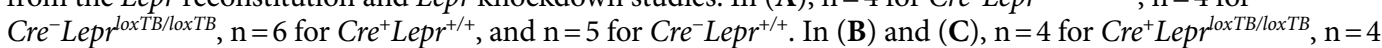

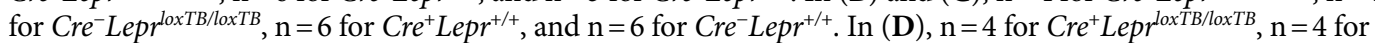
$\mathrm{Cre}^{-}$Lepr $^{\text {loxTB/loxTB }}, \mathrm{n}=5$ for Cre $\mathrm{Lepr}^{+/+}$, and $\mathrm{n}=5$ for $\mathrm{Cre}^{-} \mathrm{Lepr}^{+/+}$. In E-H, n=4 for Cre $\mathrm{Lepr}^{\text {flox/flox }}$ and $\mathrm{n}=3$ for $C r e^{-}$Lepr $^{\text {flox/flox }}$. Performed one-way ANOVA followed by Dunnett's post-hoc test for Lepr reconstitution study and unpaired t-test for Lepr knockdown study. ${ }^{*} \mathrm{p}<0.05$, Cre $^{+}$Lepr $^{\text {flox/flox }}$ vs. Cre ${ }^{-}$Lepr $^{\text {flox/flox }}$. 
controls. Our results indicate that restoration of Lepr expression in cells of myeloid lineage has beneficial effects on glucose metabolism in male mice, but its knockdown does not have a significant impact. Since recombination was less than $100 \%$, our results indicate that the remaining Lepr expression is sufficient for the maintenance of normal glucose metabolism in mice with Lepr knockdown.

Bone marrow transplantation using $d b / d b$ and wild-type mice has been used to determine the role of immune cell leptin signaling on glucose metabolism and cytokine expression, yet results have been inconsistent and both innate and adaptive immune systems are affected in this model ${ }^{20-23}$. The reasons for these inconsistent results are unclear, but different study designs, including diets, and the invasiveness of irradiation could be possible explanations. The underlying mechanisms for the improved glucose metabolism in male mice with Lepr reconstitution may involve increased adipose expression of the anti-inflammatory cytokine Il10. Leptin directly increases IL-10 secretion by macrophages ${ }^{8}$ and administration of M2 macrophages (anti-inflammatory) to mice fed a high fat diet improves their glucose tolerance while also augmenting IL-10 levels in adipose tissue and the circulation $^{42}$. Furthermore, IL-10 increases markers of M2 macrophages in adipose tissue ${ }^{43}$. Interestingly, we also found that adipose tissue Il6 expression is decreased in mice with myeloid cell-specific Lepr knockdown. IL- 6 can stimulate the bactericidicity of macrophages ${ }^{44}$ and it has already been demonstrated that macrophages from mice with myeloid cell-specific Leprb knockdown are functionally impaired in eradicating certain types of bacteria ${ }^{26}$. Hence, our results are consistent with reduced leptin signaling in macrophages causing impairments in their immunological action, possibly via diminished IL-6. Recently, Han et al. ${ }^{45}$ demonstrated that the source of IL-6 ultimately impacts its effects on glucose metabolism since adipocyte-specific Il6 knockout mice, but not myeloid cell-specific Il6 knockout mice, have improved insulin sensitivity, albeit mildly. Since we did not observe a phenotype in mice with myeloid cell-specific Lepr knockdown, it appears that the decrease in adipose tissue Il6 mRNA levels we observed in mice with Lepr knockdown is due to diminished myeloid cell-derived Il6 mRNA. In our study, adipose tissue Il6 mRNA levels were approximately twofold lower in males with myeloid cell-specific Lepr reconstitution vs. males with global Lepr transcriptional blockade. Han et al. ${ }^{45}$ found that adipocyte-specific Il6 knockout mice on high fat diet have decreased fasting blood glucose concentrations, while the opposite was found for myeloid cell-specific Il6 knockout mice on high fat diet. Since we observed improved glycemic control in mice with myeloid cell-specific Lepr reconstitution (these mice have an obese phenotype similar to mice on high fat diet), it is possible that diminished adipocyte-derived Il6 mRNA reduces adipose tissue Il6 expression and thereby contributes to the amelioration in glucose metabolism.

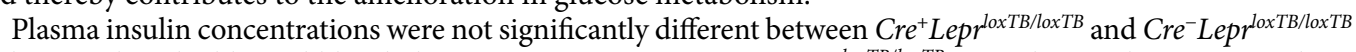
male mice, but the blunted blood glucose concentrations in $C r e^{+} L e p r^{\text {loxTB/loxTB }}$ mice during the recovery phase of the ITT ( $90 \mathrm{~min}$ and $120 \mathrm{~min}$ ) suggests that counterregulatory hormone action, including glucagon and/or corticosterone, is diminished in male mice with Lepr reconstitution. Indeed, circulating glucagon concentrations are elevated in mice with whole-body Lepr transcriptional blockade $\left(C r e^{-} \operatorname{Lepr}^{\text {loxTB/loxTB}}\right)$ and in $d b / d b$ mice, which have a comparable phenotype ${ }^{46-48}$. Interestingly, proopiomelanocortin (POMC) neuron-specific Lepr reconstitution improves glycemia, normalizes hepatic glucose output, and reduces plasma glucagon concentrations ${ }^{48}$. In our study, reduced circulating glucagon and consequently, increased insulin to glucagon ratio in the circulation may underlie the improved blood glucose concentrations and glucose tolerance observed in male mice with myeloid-cell specific Lepr reconstitution. In contrast to males, females with restored Lepr expression in myeloid cells had lower plasma insulin concentrations during the OGTT compared to females with global transcriptional blockade of Lepr, which could explain why females with Lepr reconstitution do not have improved glucose tolerance. Lastly, the increase in blood glucose concentrations in $\mathrm{Cre}^{+} \mathrm{Lepr}^{\text {loxTB/loxTB }}$ and Cre Lepr $r^{\text {loxTB/loxTB }}$ mice at $24 \mathrm{~h}$ vs. $16 \mathrm{~h}$ of fasting could be associated with the circadian rhythm of circulating glucagon in rodents ${ }^{49}$.

To the best of our knowledge, three types of myeloid cell-specific Lepr knockdown mice have been reported in the literature: Metlakunta et al. ${ }^{8}$ generated mice with knockdown of all Lepr isoforms using Lyz2Cre mice, Scheller et al. ${ }^{24}$ and Mancuso et al. ${ }^{26}$ generated mice with knockdown of the Leprb isoform using Lyz2Cre mice, and Gao et al. ${ }^{27}$ created mice with knockdown of the Leprb isoform using Cx3Cr1-Cre mice. Lyz2Cre mice were also used in our study and we targeted Leprb for knockdown. Mice with myeloid cell-specific knockdown of all receptor isoforms gained more weight on standard chow ${ }^{8}$. Although neither Scheller et al. ${ }^{25}$, nor Mancuso et $\mathrm{al}^{26}$, nor we found any differences in body weight in mice with myeloid cell-specific Leprb knockdown in younger male and female mice, Scheller et al..$^{25}$ found that old (50 weeks of age) male mice tended to weigh more than controls. Mancuso et al. ${ }^{26}$ also found that pooled male and female mice with myeloid cell-specific Leprb knockdown had elevated circulating leptin levels compared to controls at 8 weeks old, but differences in plasma leptin levels across genotypes, for each sex, did not reach statistical significance at 12 weeks old in our study. Since the age of the mice was not specified by Metlakunta et al. ${ }^{8}$, we cannot comment if deletion of different Lepr isoforms affects phenotype. In mice with myeloid-cell specific knockdown of all Lepr isoforms, the ability of leptin to lower hepatic lipids is impaired, but glucose tolerance is similar to that of controls ${ }^{8}$. Our myeloid cell-specific Leprb knockdown male and female mice did not have different circulating FFAs, glucose, insulin sensitivity, and glucose tolerance compared to controls. Hence, Lepr knockdown in cells of myeloid lineage does not have a substantial impact on body weight regulation and glucose metabolism.

We used a genetic model obesity, namely $\operatorname{Lepr}^{\text {loxTB/loxTB }}$ mice, for various reasons. First, these mice have a similar phenotype to $d b / d b$ mice, which is an extensively studied model of obesity, insulin resistance, hyperglycemia, hyperinsulinemia, hyperleptinemia, and hyperglucagonemia. Second, although an alternative to genetic obesity is high fat diet-induced obesity, mice lacking all isoforms of the leptin receptor in myeloid cells, generated using Lyz2Cre mice, have already been studied in the context of high fat diet feeding ${ }^{8}$. In that study by Metlakunta et al., on a high fat diet, mice with myeloid cell-specific Lepr knockdown had diminished body fat content, but similar body weight and glucose tolerance, to control mice. It is unclear if the glucose tolerance test results are in line with ours because the sex of the mice was not reported. However, our results are similar in that the body weight of mice with myeloid cell-specific Lepr reconstitution was comparable to the body weight 
of mice with global transcriptional blockade of Lepr $\left(L y z 2 C r e^{-} L e p r^{\text {loxTB/loxTB}}\right)$. The exception was in older age,

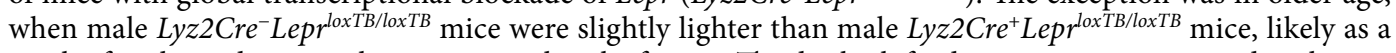
result of prolonged poorer glycemic control in the former. Third, a high fat diet regimen may not induce hyperglycemia, thereby making the discovery of possible differences in glucose metabolism challenging and limiting the potential applicability of the results to humans with uncontrolled obesity-associated diabetes. Fourth, the outcome of high fat diet studies may depend on diet composition and duration, in addition to age of the mice. Thus, genetic models of obesity likely minimize confounding variables, which may be interesting in their own right, but require a more complex study design and analysis.

Lyz2Cre mice are commonly used to study myeloid cell lineage and macrophage signaling using Cre-lox methodology. Cre-mediated excision with this transgene is limited to the innate immune system and also occurs peripherally in neutrophils and centrally in microglia ${ }^{30,31,50}$. We found approximately $75 \%$ Lepr flox recombination in bone marrow-derived macrophages. Bone marrow-derived macrophages are usually used to determine Cre-mediated excision in Lyz2Cre mice ${ }^{24,29}$, but Cre-mediated excision in myeloid cells is commonly either not reported or not quantified in studies, thereby making the recombination we obtained difficult to compare. Results from studies using reporter mice indicate that $\mathrm{Cx} 3 \mathrm{Cr} 1$-Cre can induce recombination not only in macrophages, but also microglia, granulocytes, natural killer cells and even the adaptive immune system, namely T lymphocytes and B lymphocytes (The Jackson Laboratory). Gao et al. ${ }^{27}$ used $\mathrm{Cx} 3 \mathrm{Cr} 1$-Cre mice to knock down Leprb and the increased body weight they found in mice as early as 10 weeks old was associated with diminished hypothalamic POMC neurons and morphological changes in microglia, indicating an important role for microglia in the mouse model. We did not observe changes in body weight, but we cannot exclude that Lepr signalling in microglia was affected in our models.

In conclusion, male mice with myeloid cell-specific Lepr reconstitution have improved glucose metabolism, yet are still hyperglycemic compared to lean controls. While there is debate in the literature whether leptin can adversely affect inflammatory status of immune cells, and consequently, glucose metabolism, our results indicate that leptin signaling in the innate immune system has beneficial metabolic effects, at least in male mice.

\section{Data availability}

The datasets generated during and/or analysed during the current study are available from the corresponding author on reasonable request.

Received: 4 June 2021; Accepted: 23 August 2021

Published online: 15 September 2021

\section{References}

1. Perry, R. J. et al. Hepatic acetyl CoA links adipose tissue inflammation to hepatic insulin resistance and type 2 diabetes. Cell 160, 745-758. https://doi.org/10.1016/j.cell.2015.01.012 (2015).

2. Schenk, S. et al. Insulin sensitivity: Modulation by nutrients and inflammation. J. Clin. Invest. 118, 2992-3002. https://doi.org/10. 1172/JCI34260 (2008).

3. Zarkesh-Esfahani, H. et al. High-dose leptin activates human leukocytes via receptor expression on monocytes. J. Immunol. 167, 4593-4599 (2001).

4. Shen, J. et al. Leptin enhances TNF-alpha production via p38 and JNK MAPK in LPS-stimulated Kupffer cells. Life Sci. 77, 1502-1515 (2005).

5. Lee, S. M. et al. Leptin increases TNF-alpha expression and production through phospholipase D1 in Raw 264.7 cells. PLoS ONE 9, e102373. https://doi.org/10.1371/journal.pone.0102373 (2014).

6. Shivahare, R. et al. Leptin augments protective immune responses in murine macrophages and enhances potential of miltefosine against experimental visceral leishmaniasis. Acta Trop. 150, 35-41. https://doi.org/10.1016/j.actatropica.2015.06.024 (2015).

7. Acedo, S. C. et al. Participation of leptin in the determination of the macrophage phenotype: An additional role in adipocyte and macrophage crosstalk. In Vitro Cell Dev. Biol. Anim. 49, 473-478. https://doi.org/10.1007/s11626-013-9629-x (2013).

8. Metlakunta, A. et al. Kupffer cells facilitate the acute effects of leptin on hepatic lipid metabolism. Am. J. Physiol. Endocrinol. Metab. 312, E11-E18. https://doi.org/10.1152/ajpendo.00250.2016 (2017).

9. Maeda, T. et al. Leptin derived from adipocytes in injured peripheral nerves facilitates development of neuropathic pain via macrophage stimulation. Proc. Natl. Acad. Sci. USA 106, 13076-13081. https://doi.org/10.1073/pnas.0903524106 (2009).

10. Wang, B. et al. Leptin- and leptin receptor-deficient rodent models: Relevance for human type 2 diabetes. Curr. Diabetes Rev. 10, 131-145 (2014).

11. Osborn, O. et al. Metabolic characterization of a mouse deficient in all known leptin receptor isoforms. Cell Mol. Neurobiol. 30, 23-33. https://doi.org/10.1007/s10571-009-9427-x (2010).

12. Bates, S. H. \& Myers, M. G. Jr. The role of leptin receptor signaling in feeding and neuroendocrine function. Trends Endocrinol. Metab. 14, 447-452 (2003).

13. Brann, D. W. et al. Leptin and reproduction. Steroids 67, 95-104 (2002).

14. Bjorbaek, C. et al. Divergent signaling capacities of the long and short isoforms of the leptin receptor. J. Biol. Chem. 272, 3268632695 (1997).

15. Zhou, Y. et al. Leptin deficiency shifts mast cells toward anti-inflammatory actions and protects mice from obesity and diabetes by polarizing M2 macrophages. Cell Metab. 22, 1045-1058. https://doi.org/10.1016/j.cmet.2015.09.013 (2015).

16. Li, S. L. et al. Enhanced proatherogenic responses in macrophages and vascular smooth muscle cells derived from diabetic $\mathrm{db} / \mathrm{db}$ mice. Diabetes 55, 2611-2619 (2006).

17. Zykova, S. N. et al. Altered cytokine and nitric oxide secretion in vitro by macrophages from diabetic type II-like $\mathrm{db} / \mathrm{db}$ mice. Diabetes 49, 1451-1458 (2000).

18. Fantuzzi, G. Three questions about leptin and immunity. Brain Behav. Immun. 23, 405-410. https://doi.org/10.1016/j.bbi.2008.10. 007 (2009).

19. Sherry, C. L. et al. Augmented lipopolysaccharide-induced TNF-alpha production by peritoneal macrophages in type 2 diabetic mice is dependent on elevated glucose and requires p38 MAPK. J. Immunol. 178, 663-670 (2007).

20. Gove, M. E. et al. Generation of leptin receptor bone marrow chimeras: Recovery from irradiation, immune cellularity, cytokine expression, and metabolic parameters. Obesity (Silver Spring) 18, 2274-2281. https://doi.org/10.1038/oby.2010.84 (2010). 
21. Li, M. et al. Successful modulation of type 2 diabetes in $\mathrm{db} / \mathrm{db}$ mice with intra-bone marrow-bone marrow transplantation plus concurrent thymic transplantation. J. Autoimmun. 35, 414-423. https://doi.org/10.1016/j.jaut.2010.09.001 (2010).

22. Gutierrez, D. A. \& Hasty, A. H. Haematopoietic leptin receptor deficiency does not affect macrophage accumulation in adipose tissue or systemic insulin sensitivity. J. Endocrinol. 212, 343-351. https://doi.org/10.1530/JOE-11-0338 (2012).

23. Dib, L. H. et al. Bone marrow leptin signaling mediates obesity-associated adipose tissue inflammation in male mice. Endocrinology 155, 40-46. https://doi.org/10.1210/en.2013-1607 (2014).

24. Scheller, E. L. et al. Leptin functions peripherally to regulate differentiation of mesenchymal progenitor cells. Stem Cells $\mathbf{2 8}$, 1071-1080. https://doi.org/10.1002/stem.432 (2010).

25. Scheller, E. L. et al. A potential role for the myeloid lineage in leptin-regulated bone metabolism. Horm. Metab. Res. 44, 1-5. https:// doi.org/10.1055/s-0031-1297971 (2012).

26. Mancuso, P. et al. Ablation of the leptin receptor in myeloid cells impairs pulmonary clearance of Streptococcus pneumoniae and alveolar macrophage bactericidal function. Am. J. Physiol. Lung Cell Mol. Physiol. 315, L78-L86. https://doi.org/10.1152/ajplung. 00447.2017 (2018).

27. Gao, Y. et al. Deficiency of leptin receptor in myeloid cells disrupts hypothalamic metabolic circuits and causes body weight increase. Mol. Metab. 7, 155-160 (2018).

28. Clausen, B. E. et al. Conditional gene targeting in macrophages and granulocytes using LysMcre mice. Transgenic Res. 8, 265-277 (1999).

29. Spadaro, O. et al. IGF1 shapes macrophage activation in response to immunometabolic challenge. Cell Rep. 19, 225-234. https:// doi.org/10.1016/j.celrep.2017.03.046 (2017).

30. Abram, C. L. et al. Comparative analysis of the efficiency and specificity of myeloid-Cre deleting strains using ROSA-EYFP reporter mice. J. Immunol. Methods 408, 89-100. https://doi.org/10.1016/j.jim.2014.05.009 (2014).

31. Kanter, J. E. et al. Diabetes promotes an inflammatory macrophage phenotype and atherosclerosis through acyl-CoA synthetase 1. Proc. Natl. Acad. Sci. USA 109, E715-724. https://doi.org/10.1073/pnas.1111600109 (2012).

32. Huynh, F. K. et al. Disruption of hepatic leptin signaling protects mice from age- and diet-related glucose intolerance. Diabetes 59, 3032-3040. https://doi.org/10.2337/db10-0074 (2010).

33. Balthasar, N. et al. Leptin receptor signaling in POMC neurons is required for normal body weight homeostasis. Neuron $\mathbf{4 2}$, 983-991 (2004).

34. McMinn, J. E. et al. An allelic series for the leptin receptor gene generated by CRE and FLP recombinase. Mamm. Genome 15, 677-685 (2004).

35. Pereira, S. et al. Metabolic effects of leptin receptor knockdown or reconstitution in adipose tissues. Sci. Rep. 9, 3307 (2019).

36. Denroche, H. C. et al. Leptin therapy reverses hyperglycemia in mice with streptozotocin-induced diabetes, independent of hepatic leptin signaling. Diabetes 60, 1414-1423. https://doi.org/10.2337/db10-0958 (2011).

37. Clementi, A. H. et al. Deletion of interleukin- 6 improves pyruvate tolerance without altering hepatic insulin signaling in the leptin receptor-deficient mouse. Metabolism 60, 1610-1619 (2011).

38. Pineda-Torra, I. et al. Isolation, culture, and polarization of murine bone marrow-derived and peritoneal macrophages. Methods Mol. Biol. 1339, 101-109. https://doi.org/10.1007/978-1-4939-2929-0_6 (2015).

39. Erener, S. et al. Inflammasome-activated caspase 7 cleaves PARP1 to enhance the expression of a subset of NF-kappaB target genes. Mol. Cell 46, 200-211. https://doi.org/10.1016/j.molcel.2012.02.016 (2012).

40. Aljanabi, S. M. \& Martinez, I. Universal and rapid salt-extraction of high quality genomic DNA for PCR-based techniques. Nucleic Acids Res. 25, 4692-4693 (1997).

41. Yoon, Y. S. et al. Adiponectin and thiazolidinedione targets CRTC2 to regulate hepatic gluconeogenesis. Exp. Mol. Med. 41, 577-583 (2009).

42. Vega-Galaviz, D. et al. M2 macrophage immunotherapy abolishes glucose intolerance by increasing IL-10 expression and AKT activation. Immunotherapy 12, 9-24. https://doi.org/10.2217/imt-2019-0080 (2020).

43. Fujisaka, S. et al. Regulatory mechanisms for adipose tissue M1 and M2 macrophages in diet-induced obese mice. Diabetes 58, 2574-2582. https://doi.org/10.2337/db08-1475 (2009).

44. Hop, H. T. et al. Interleukin 6 promotes Brucella abortus clearance by controlling bactericidal activity of macrophages and CD8(+) T cell differentiation. Infect. Immun. https://doi.org/10.1128/iai.00431-19 (2019).

45. Han, M. S. et al. Regulation of adipose tissue inflammation by interleukin 6. Proc. Natl. Acad. Sci. USA 117, 2751-2760. https:// doi.org/10.1073/pnas.1920004117 (2020).

46. Davis, R. C. et al. Early hepatic insulin resistance precedes the onset of diabetes in obese C57BLKS-db/db mice. Diabetes 59, 1616-1625. https://doi.org/10.2337/db09-0878 (2010).

47. Burke, S. J. et al. $\mathrm{db} / \mathrm{db}$ mice exhibit features of human type 2 diabetes that are not present in weight-matched C57BL/6J mice fed a western diet. J. Diabetes Res. 2017, 8503754. https://doi.org/10.1155/2017/8503754 (2017).

48. Berglund, E. D. et al. Direct leptin action on POMC neurons regulates glucose homeostasis and hepatic insulin sensitivity in mice. J. Clin. Investig. 122, 1000-1009. https://doi.org/10.1172/JCI59816 (2012).

49. Ruiter, M. et al. The daily rhythm in plasma glucagon concentrations in the rat is modulated by the biological clock and by feeding behavior. Diabetes 52, 1709-1715 (2003).

50. Kim, H. J. et al. Deficient autophagy in microglia impairs synaptic pruning and causes social behavioral defects. Mol. Psychiatry 22, 1576-1584. https://doi.org/10.1038/mp.2016.103 (2017).

\section{Acknowledgements}

This work was supported by a Grant from the Canadian Institutes of Health Research (CIHR) awarded to T.J.K. S.P. was supported by a CIHR postdoctoral fellowship.

\section{Author contributions}

S.P. and T.J.K. designed the study, with assistance from S.M.O., S.E., and S.D.C. Experiments were performed by S.P., D.L.C., M.C., K.C., J.S.Y., S.M.O., C.E.E., M.M.G., R.K.B., and T.D.W. Data were analyzed by S.P., K.C., J.S.Y., and T.D.W. S.P. and T.J.K. wrote the manuscript.

\section{Competing interests}

The authors declare no competing interests.

\section{Additional information}

Supplementary Information The online version contains supplementary material available at https://doi.org/ 10.1038/s41598-021-97549-0.

Correspondence and requests for materials should be addressed to T.J.K. 
Reprints and permissions information is available at www.nature.com/reprints.

Publisher's note Springer Nature remains neutral with regard to jurisdictional claims in published maps and institutional affiliations.

(c) (i) Open Access This article is licensed under a Creative Commons Attribution 4.0 International License, which permits use, sharing, adaptation, distribution and reproduction in any medium or format, as long as you give appropriate credit to the original author(s) and the source, provide a link to the Creative Commons licence, and indicate if changes were made. The images or other third party material in this article are included in the article's Creative Commons licence, unless indicated otherwise in a credit line to the material. If material is not included in the article's Creative Commons licence and your intended use is not permitted by statutory regulation or exceeds the permitted use, you will need to obtain permission directly from the copyright holder. To view a copy of this licence, visit http://creativecommons.org/licenses/by/4.0/.

(C) The Author(s) 2021 